\title{
Contaminant mass discharge to streams: Comparing direct groundwater velocity measurements and multi-level groundwater sampling with an in-stream approach
}

Rønde, Vinni; McKnight, Ursula S.; Sonne, Anne Thobo; Balbarini, Nicola; Devlin, J.F.; Bjerg, Poul Løgstrup

Published in:

Journal of Contaminant Hydrology

Link to article, DOI:

10.1016/j.jconhyd.2017.09.010

Publication date:

2017

Document Version

Peer reviewed version

Link back to DTU Orbit

Citation (APA):

Rønde, V., McKnight, U. S., Sonne, A. T., Balbarini, N., Devlin, J. F., \& Bjerg, P. L. (2017). Contaminant mass discharge to streams: Comparing direct groundwater velocity measurements and multi-level groundwater sampling with an in-stream approach. Journal of Contaminant Hydrology, 206, 43-54.

https://doi.org/10.1016/j.jconhyd.2017.09.010

\section{General rights}

Copyright and moral rights for the publications made accessible in the public portal are retained by the authors and/or other copyright owners and it is a condition of accessing publications that users recognise and abide by the legal requirements associated with these rights.

- Users may download and print one copy of any publication from the public portal for the purpose of private study or research.

- You may not further distribute the material or use it for any profit-making activity or commercial gain

- You may freely distribute the URL identifying the publication in the public portal 


\section{Accepted Manuscript}

Contaminant mass discharge to streams: Comparing direct groundwater velocity measurements and multi-level groundwater sampling with an in-stream approach

V. Rønde, U.S. McKnight, A.Th. Sonne, N. Balbarini, J.F. Devlin, P.L. Bjerg

PII: S0169-7722(17)30207-3

DOI: doi:10.1016/j.jconhyd.2017.09.010

Reference: CONHYD 3341

To appear in: Journal of Contaminant Hydrology

Received date: 12 July 2017

Revised date: 15 September 2017

Accepted date: 22 September 2017

Please cite this article as: V. Rønde, U.S. McKnight, A.Th. Sonne, N. Balbarini, J.F. Devlin, P.L. Bjerg , Contaminant mass discharge to streams: Comparing direct groundwater velocity measurements and multi-level groundwater sampling with an instream approach. The address for the corresponding author was captured as affiliation for all authors. Please check if appropriate. Conhyd(2017), doi:10.1016/ j.jconhyd.2017.09.010

This is a PDF file of an unedited manuscript that has been accepted for publication. As a service to our customers we are providing this early version of the manuscript. The manuscript will undergo copyediting, typesetting, and review of the resulting proof before it is published in its final form. Please note that during the production process errors may be discovered which could affect the content, and all legal disclaimers that apply to the journal pertain. 
Contaminant mass discharge to streams: comparing direct ground water velocity measurements and multi-level groundwater sampling with an in-stream approach

\author{
V. Rønde ${ }^{1 *}$, U.S. McKnight ${ }^{1}$, A.Th. Sonne ${ }^{1}$, N. Balbarini ${ }^{1}$, J.F. Devlin ${ }^{2}$, and P.L. Bjerg ${ }^{1}$ \\ ${ }^{1}$ Department of Environmental Engineering, Technical University of Denmark, Kgs. Lyngby, Denmark. \\ ${ }^{2}$ Department of Geology, University of Kansas, Lawrence, KS, United States \\ *Corresponding author. Email address: vikar@env.dtu.dk (V. Rønde).
}

Keywords:

Contaminant mass discharge; Contaminant flux; Groundwater-surface water interaction; Risk assessment;

Point Velocity Probe; PVP

Submitted for Journal of Contaminant Hydrology, July 2017 


\section{Introduction}

Contaminated sites pose a high risk to water resources, as contaminants such as chlorinated ethenes can impact groundwater-dependent drinking waters and migrate via ground water to surface water bodies, with associated extensions to human health and ecological risks (Ellis and Rivett, 2007; McKnight et al., 2010). Application of the contaminant mass discharge approach has been accepted as a supplement to concentrationbased risk assessment (Basu et al., 2006), as it links sources and their impacts on receptors, e.g. streams (Conant et al., 2004; Milosevic et al., 2012). The contaminant mass discharge is defined as the total contaminant mass per unit time that passes through a control plane that is oriented perpendicular to the groundwater flow direction, and that extends over the entire width and depth of the plume (Basu et al., 2006; ITRC, 2010). When assessing the risk posed to a stream, the contaminant mass discharge is especially us eful, since it can be used to simulate prospective in-stream contaminant concentrations (Aisopou et al., 2015). These concentrations can be compared to existing surface water quality criteria used in concentration-based risk assessment (Newell et al., 2011; Verreydt et al., 2012).

The most common method to quantify the groundwater-borne contaminant mass discharge is based on multilevel data collected along a control plane (Barbaro and Neupane, 2006; Béland-Pelletier et al., 2011; Bockelmann et al., 2003; Kübert and Finkel, 2006; Troldborg et al., 2012) . It includes the more conventional method in which individual data points of groundwater concentration and waterflux are integrated (e.g. Barbaro and Neupane, 2006; Bockelmann etal., 2003), as well as the method where the average flux is measured directly over a given time period by Passive Fl ux Meters (PFMs) to which contaminants sorb while deployed in wells (Annable et al., 2005; Klammler et al., 2012). Another method is the integral approach, based on data from pumping campaigns conducted at one or more wells combined with additional groundwater flux data (Bauer et al., 2004; Bayer-Raich et al., 2006; Béland-Pelletier et al., 2011; Bockelmann et al., 2003; Goltzet al., 2009; Herold et al., 2009; Jarsjö et al., 2005; Zeru and Schäfer, 2005).

Field-estimated contaminant mass discharges are associated with relatively high uncertainty, however, and reliable estimates may be an even greater challenge to obtain close to streams for two primary reasons. Firstly, a high spatial variability in contaminant concentrations is often found at the groundwater-surface water interface. This may be related to contaminant source characteristics, variabil ity in hydraulic conductivity and thus groundwaterfluxes, and/or hyporheic zone characteristics. For example, Conant et al. (2004) observed a variation in the streambed concentrations of chlorinated ethenes by a factor of 100-10,000 over lateral 
distances of 1-3.5 m, while Freitas et al. (2015) found that the mixing within the hyporheiczone resulted in the dilution of a discharging chlorinated hydrocarbon plume in some locations (i.e. indicating spatial dependence), as well as enhanced dechlorination. Such variabilities call for a high density of sampling points to properly characterize a contaminant plume.

Secondly, the groundwater-surface water interface is often characterised by a multi-directional groundwater flow field (as opposed to horizontal ground water flow in locations farfrom surface water bodies), including large temporal and spatial variations in the exchange of water fluxes (Karan et al., 2014; Keery et al., 2007; Wroblicky et al., 1998), spatial variability in hydraulic gradients (Storey, 2003), transient mixing in the hyporheic zone (Freitas et al., 2015) and varying ground water velocities and flow directions at stream meanders (Kasahara and Hill, 2007). This naturally links back to, but cannot entirely explain, the high spatialvariability in contaminant concentration as described above. Temporal variations are strongly linked to precipitation patterns, while spatial variations are caused by stream geometry (Balbarini et al., 2016) and variability in the hydraulic conductivity (Calver, 2001; Nowinski et al., 2011; Sebok et al., 2015). Due to this variability, Darcy's law-based calculations might not be definitive in estimating specific discharge close to streams. Other methods to measure groundwaterfluxes include tracer tests, seepage meters and heat tracer methods (Kalbus et al., 2006).

An alternative method to measure groundwaterfluxinvolves the direct measurement of groundwater velocity using the Point-Velocity Probe (PVP), which can measure the seepage velocity based on the travel time of a tracer between an injection port and several detectors located on a small cylindrical probe (Devlin et al., 2009; Labaky et al., 2007). This technique has an advantage over other methods because it does not require hydraulic conductivity or gradient values, which may introduce high levels of uncertainty. It also avoids the use of wells, which can introduce considerable uncertainty to groundwater velocity measurements. The PVP has been shown to be a promising tool for groundwater velocity measurements in several studies (Devlin et al., 2009; Kempf et al., 2013; Schillig et al., 2016, 2011). Nevertheless, studies are still lacking in which PVPs are combined with multi-level groundwater sampling for the quantification of the contaminant mass discharging to streams.

To address the issue regarding uncertainty of the contaminant mass discharge estimates, several studies have focused on linking the uncertainty with the density of sampling points and aquifer heterogeneity (BélandPelletier et al., 2011; Cai et al., 2011; Kübert and Finkel, 2006; Troldborg et al., 2012, 2010). They found that the relative uncertainty of the contaminant mass discharge increases with increasing aquifer heterogeneity and 
decreasing number of sampling points, and hence that the choice of field method for contaminant mass discharge estimation will be site specific. However, since the "true" value of the total contaminant mass discharge across a defined control plane is typically unknown at field sites, these studies have not been able to fully assess the accuracy of their estimates at the field scale.

A method-not previously explored -to assess the accuracy of the contaminant mass discharge obtained from stream bank investigations is to compare with a second estimate (termed the in-stream contaminant mass discharge), which can be calculated from completely mixed stream concentrations and corresponding stream discharge (Aisopou et al., 2015). This in-stream estimate can indicate whether the entire contaminant mass has been accounted for by the control plane approach and is thus useful for evaluation of the particular field methods applied to estimate the contaminant mass discharging to a stream.

In this study, we use the low-land Grindsted stream as a study site. The stream has a discharge of ca. $2000 \mathrm{~L} / \mathrm{s}$ and drains a sandy aquifer. It is impacted by a chlorinated ethene plume from a former pharmaceutical factory. We aim to evaluate direct velocity measurements, using PVPs, combined with multi-level groundwater sampling to quantify contaminant mass discharge to a stream. We further compare these results with those from contaminant mass discharge estimations calculated by combining multi-level groundwater sampling with a specific discharge obtained from Darcy's law using the geometric mean of the hydraulic conductivity and a gradient measured at the groundwater-surface water interface.

The second aim of this work is to compare the three estimates of contaminant mass discharge at the stream bank with the in-stream contaminant mass discharge obtained from a relationship between completely mixed stream concentrations and corresponding stream discharge. Due to its integrated nature, we believe that the in-stream mass discharge is reasonably close to the "true" value in this case. Since dilution commonly renders contaminant concentrations in well-mixed streams too low to measure repeatedly and confidently (e.g. Conant et al., 2004; Westbrook et al., 2005), our study site provides an uncommon opportunity to compare the contaminant mass discharge estimates at the stream bank with estimates in the stream itself.

\section{Study site}

The study was conducted along a $250 \mathrm{~m}$ reach of Grindsted stream located in central Jutland, Denmark (Figure 1). The stream is 8-12 $\mathrm{m}$ wide and 1-2.5 m deep, and drains a catchment of ca. $200 \mathrm{~km}^{2}$. The average annual precipitation in the area is $800 \mathrm{~mm} / \mathrm{y}$ (1961-1990) (DMI, 2016). The stream flows westward through 
Grindsted town with a discharge ranging from 1200-4500 L/s with an annual average of ca. $2000 \mathrm{~L} / \mathrm{s}$ (Figure S1 in the supporting information (SI)). The aquifer in the region is ca. $80 \mathrm{~m}$ thick, unconfined and hydrologically connected to the stream (Balbarini et al., 2016). It consists of an upper Quaternary sandy layer underlain by a Tertiary sandy layer (Heron et al., 1998). Below, a thick and extensive Tertiary clay layer comprises the regional aquitard (Barlebo et al., 1998; Heron et al., 1998). Rügge et al. (1999) estimated the mean porosity to be 0.37 for the Quaternary deposits.

The contaminated site, Grindsted factory, is located $1.5 \mathrm{~km}$ north of the stream (Figure $1 \mathrm{~A}$ ). The site is the source of groundwater pollutants including chlorinated solvents (tetrachloroethylene (PCE) and trichloroethylene (TCE)), barbiturates and sulfonamides. All the pollutants originate from the production of pharmaceutical compounds at the former Grindsted factory. Chlorinated solvents and their degradation products, pharmaceuticals, and BTEX compounds have all been detected in the Grindsted stream water (Rasmussen et al., 2016; Sonne et al., 2017), indicating one or more contaminant plumes discharging to the stream. Water also discharges into the stream through two partially submerged culverts (Figure 1C, D) originating from a former wastewater treatment plant located ca. $50 \mathrm{~m}$ north of the investigated stream reach. 


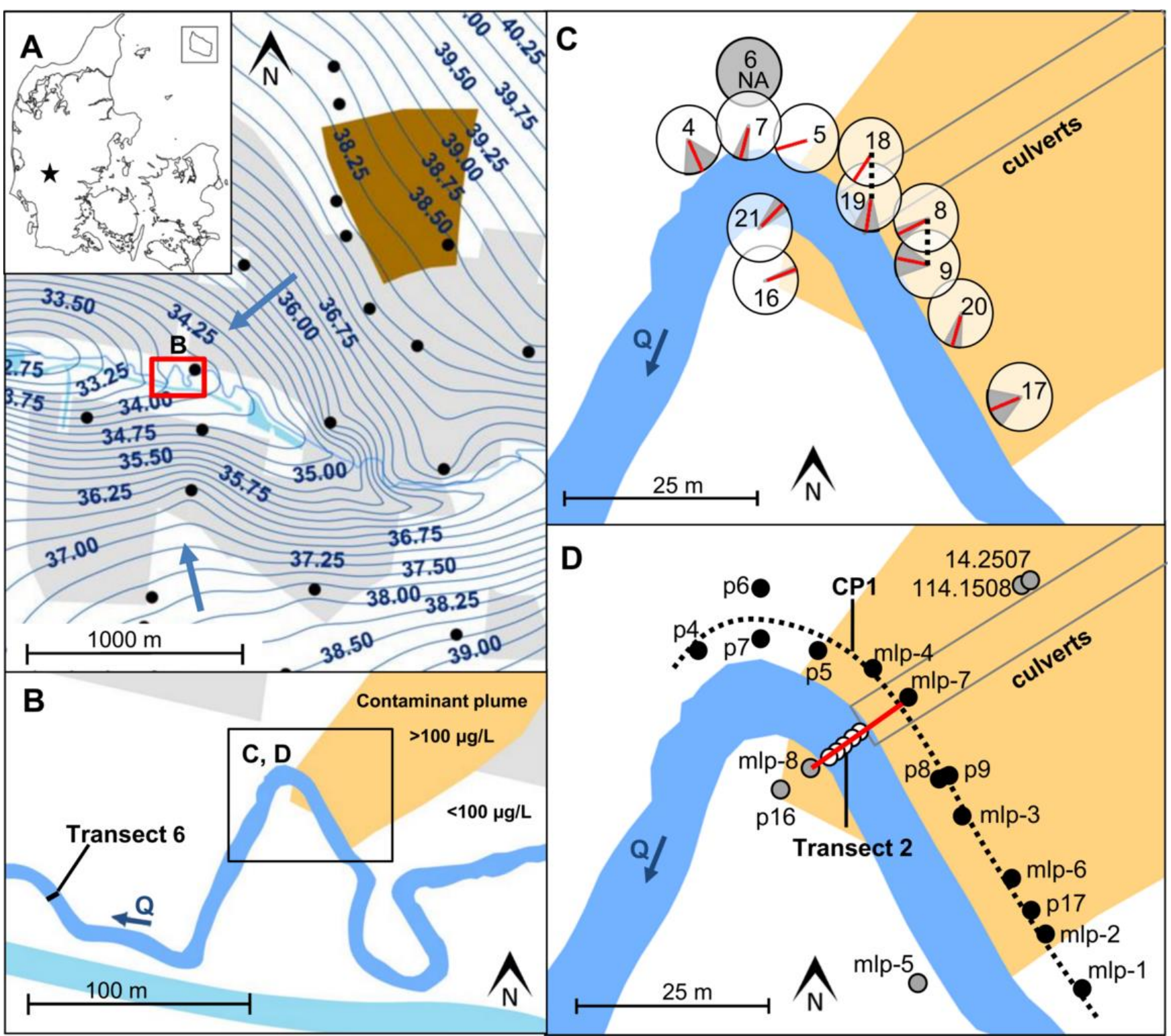

Figure 1: A) Map showing Grindsted stream (light blue curvature), Grindsted factory site (brown area), and the location of the study site (red rectangle). Dark blue lines and corresponding values show the grou ndwater equipotentials in meters in the Danish Vertical reference system (DVR90), i.e. meters above sea level ( $m$ asl) based on data from wells (black circles) (additional wells used for this purpose are located outside the map). The arrows indicate the ground water flow direction. In the upper left corner, the location of Grindsted is shown on a map of Denmark. B) Map of the study site showing a plan view of a contaminant plume discharging to the stream developed based on this study. The outline of the plume is the $100 \mu \mathrm{g} / \mathrm{L}$ contour line for viny/chloride expressed as PCE equivalents (PCE eq) at $31 \mathrm{~m}$ asl $( \pm 0.5 \mathrm{~m}$ ) based on water samples collected from wells in 
Figure 1D (see SI Table S1 forconcentration values). The equipotential lines in Figure 1A have been used to extend this contour line upgradient. C) Enlargement of the plume discharge zone showing the location of two culverts and the installed PVPs (numbered circles). Two PVP pairs, shown to be connected by a vertical dotted line, are installed in the same borehole at different depths. The red lines within the circles show the horizontal average groundwaterflow direction measured with the PVPs, while the grey areas indicate \pm 1 standard deviation based on measurements from Nov. 2013 - Nov. 2015. D) Enlargement of the plume discharge zone showing the location of wells (grey and black circles) and streambed piezometers (white circles). A control plane, CP1 (curved dotted line), is comprised of the wells represented by black circles. The transect across the stream, Transect 2 (red line), is comprised of both the streambed piezometers and wells m/p-7 and m/p-8.

\section{Materials and methods}

From Nov. 2013 to Mar. 2017 the following investigations werecarried out at the study site:PVP tracer injections were conducted to measure the ground water seepage velocity and flow direction; slug tests and hydraulic head measurements were conducted to obtain the specific discharge from Darcy's law; samples of groundwater, stream water and water below the streambed were collected to measure the chlorinated ethene concentration; and finally, the stream discharge was measured up-and downstream of the study site.

\subsection{PVP measurements of groundwater velocity}

PVPs, functioning on the same principle as described in Labaky et al. (2007), were constructed to measure the groundwatervelocity in the plume discharge zone at the stream bank. However, they were equipped with three injection ports instead of only one. This modification was made to ensure that at least one of the ports was appropriately oriented in the flow system to measure groundwater velocity at locations with an unknown groundwater flow direction. For further details on the PVP design, see SI Figure S2 and corresponding description. The PVPs were installed in open boreholes allowing sediments to collapse around them. Installation locations are shown in Figure 1C.

The magnitude and direction of ground water flow were investigated by conducting a total of 143 PVP tracer injections from Nov. 2013 to Nov. 2015 in 12 probes installed along the stream bank. The injections were conducted by manually injecting a small amount of saline tracer $(0.5-2.0 \mathrm{~mL}$ of a $1-2 \mathrm{~g} \mathrm{NaCl} / \mathrm{L} \mathrm{milliQ}$ water solution) while recording the solution resistivity at the PVP detectors. 
Some PVP tests did not produce any breakthrough curves and thus had to be discarded. The explanation for this is likely that the injection was conducted from a poorly orientated port, resulting in tracer transport away from the probe instead of around it. This is not a surprise, as groundwater flow directions can vary considerably at the point scale, as demonstrated by Labaky et al. (2009) and Schillig et al. (2016). In addition, PVP6never produced any useable signals, possibly due to damage incurred during installation. Altogether, 89 datasets were considered suitable for analysis by fitting tracer breakthrough curves using the program VelProbePE3 (Schillig, 2012). For 31 datasets, signals were only obtained from one detector on the probe (signals from two detectors are required to uniquelyestimate flow direction). In these cases the mean flow direction of the remaining tests conducted at the particular PVP was used in the calculation of groundwater velocity.

\subsection{Slug tests and hydraulichead}

Hydraulic conductivity values and hydraulic heads were measured across the study site. Hydraulic conductivity was measured by conducting 47 falling head mini-slug tests at multiple depths along a control plane, CP1, at the north stream bank (locations are indicated by black circles in Figure 1D). The tests were conducted in 19 $\mathrm{mm}$ inner diameter drive point piezometers with $10 \mathrm{~cm}$ long screens that were driven into the ground. Prior to each test, a pressure transducer, recording every $0.5 \mathrm{~s}$, was submerged inside the piezometer and the set-up was allowed to equilibrate. The water level was then raised ca. $1 \mathrm{~m}$ by vacuum, after which the vacuum was released to let the water level drop (see Hinsby et al. (1992) for further details on the method). The Bouwer \& Rice method (Bouwer and Rice, 1976; Springer and Gelhar, 1991) was used to calculate the horizontal hydraulic conductivity, assuming an anisotropy factor of 10 between the vertical and horizontal hydraulic conductivities. A hydraulic conductivity profile was obtained from ordinary kriging using the gstat package in R software (v3.3.1). An exponential variogram model was applied using an anisotropy factor of 10.

In May 2015, the hydraulichead was measured at multiple depths along a transverse transect (Trans ect 2) consisting of five streambed piezometers (named k1-5) and the wells mlp-7 and mlp-8at the north and south stream bank, respectively (see Figure 1D and 2). The measurements were conducted in drive point piezometers similar to the ones used for slug testing.

\subsection{Groundwater sampling at the bank and below the streambed}

To obtain the contaminant concentrations along CP1, groundwater samples at multiple depths were collected in a dense sampling grid during three field campaigns in Oct. 2014, May 2015 and Sep. 2016 (see Figure 1D and 
Figure 3). Also a few samples were collected at the south bank. The samples were collected from drive-point piezometers (similar to the ones used for slug testing) that were purged by 3 volumes of standing water before sample collection, and then driven further into the ground for further purging and sample collection. The samples were collected in 20 or $40 \mathrm{~mL}$ glass vials capped with Teflon septa, sealed without air bubbles in the vials, and preserved with $4 \mathrm{M}$ sulfuric acid to prevent contaminant degradation during storage. The samples were immediately transferred to a cooler and stored at $10^{\circ} \mathrm{C}$ until the time of analysis (1-3 weeks later).

Results from the first sampling campaign showed that high concentrations were found at the deepest points, i.e. the plume had not been delineated in the vertical direction. Therefore, to prevent an underestimation of the contaminant mass discharge, even deeper points were sampled in the second and third campaigns. To assess the consistency of concentrations along the investigated stream reach from one campaign to the other, 10 overlapping points were sampled. The overlapping samples compared well; at points with a vinyl chloride concentration $>100 \mu \mathrm{g} / \mathrm{L}$ (PCE eq), the values were within $35 \%$ of the mean (Figure 3 ) indicating limited temporal variation. The same trend was observed for cis-DCE (SI Figure S3).

The May 2015 sampling campaign also included the collection of water samples from below the streambed at multiple depths $(0.5,1,2$ and $3 \mathrm{~m}$ below the streambed) from the five streambed piezometers along Transect 2 (see Figure 1D and Figure 2). The samples were preserved and stored in a fashion similar to the groundwater samples. A concentration profile at Transect 2 was obtained from ordinary kriging using the gstat package in $R$ software (v3.3.1). A spherical variogram model was applied using an anisotropy factor of 10.

\subsection{Determination of contaminant input from culverts}

It was discovered that input to the stream occurred both by groundwater discharge and through two partially submerged culverts continuously discharging water to the stream (Figure $1 C, D$ ). To determine the contaminant mass discharge from the culverts, water samples were collected and analyze $d$ for chlorinated ethenes in Nov. and Dec. 2014. At the same time, the discharge through the culverts was measured by timing the filling of a bucket of known volume. Water sampling and discharge measurements were conducted at the inlet to the culverts.

\subsection{Stream discharge}

The stream discharge was obtained from stream water levels monitored daily from Jan. 2013 to Mar. 2015 at two gauging stations, located upstream (station 31.28) and downstream (station 31.14) of the study area (see 
hydrographs in SI Figure S1). To establish a relationship between water level and stream discharge, 26 independent manual measurements of the stream level and discharge were conducted at each of the two gauging stations.

\subsection{Stream water sampling}

Prior sampling of the stream water column vertically al ong Transect 2 (data not shown), and supporting model simulations of Grindsted stream (Aisopou et al. 2015) established that vertical mixing in the channel was more rapid than transverse mixing. Therefore, to determine the location of the fully mixed point, it was only necessary to determine the location where transverse mixing was complete. This was done by collecting water samples from the middle of the stream water column along 6 transverse transects, over 5 sampling campaigns (Aug. 2012, May, Aug. and Oct. 2014, and Nov. 2015).

The variation in stream concentrations with stream discharge was investigated by collecting samples in the centre of the stream, from the middle of the water column, at transect 6 (Figure 1B) in an additional 7 sampling campaigns (Aug. 2012, Apr., May, Jun., Aug. and Oct. 2014, and Mar. 2015). Since the streamflow varies throughout the year, the campaigns represent different stream discharges that can help establish a relationship between the fully mixed stream concentration and corresponding discharge. All samples were preserved and stored in the same fashion as the groundwater samples.

\subsection{Chemical analysis}

The analysis of chlorinated ethenes was conducted by Gas Chromatography Mass Spectrometry (GC-MS) head space. A subsample from each vial was transferred to a GC-MS vial containing an internal standard (chloroform), and then incubated in a rotary shaker at $85^{\circ} \mathrm{C}$ for 5 min prior to injection. Calibration and control solutions were included in the analysis. $250 \mu \mathrm{L}$ headspace of each GC-MS vial was injected into a gas chromatograph (Agilent 7980 ) equipped with an electron impact $(70 \mathrm{eV})$ triple-axis mass-selective detector (Agilent $5675 \mathrm{C}$ ) and a HP-PLOT/Q capillary column ( $30 \mathrm{~m} \times 0.32 \mathrm{~mm} \times 20 \mu \mathrm{m}$ ) with helium as a carrier gas. The column temperature was $40^{\circ} \mathrm{C}$ for the first $4 \mathrm{~min}$ and then ramped at $35^{\circ} \mathrm{C} / \mathrm{min}$ until a temperature of $290^{\circ} \mathrm{C}$ was reached and held for $7 \mathrm{~min}$. The method's quantification limits never exceeded $0.03 \mu \mathrm{g} / \mathrm{L}$.

\section{Calculation of contaminant mass discharge}


The contaminant mass discharge for the total chlorinated ethenes, as well as for PCE, TCE, cis-1,2dichloroethylene (cis-DCE) and vinyl chloride, was quantified by two distinct approaches: the control plane and the in-stream approaches. The first approach used the specific discharge together with measured groundwater concentrations to calculate the contaminant mass discharge at the stream bank, while the second approach used completely mixed stream concentrations and stream discharge to determine the in-stream contaminant mass discharge. Note that a value of zero was assigned to all water samples with a concentration value either below the quantification or detection limit. These two approaches are described below.

\subsection{Contaminant mass discharge at the stream bank}

The contaminant mass discharge $\left(J_{C P}\right)$ at the stream bank was calculated from specific discharge $(q)$ and groundwater concentrations $(c)$ measured along a control plane with area $(A)$ using the formula (ITRC, 2010):

$$
J_{C P}=\sum c_{i} A_{i} q_{i}
$$

(Equation 1)

where $i$ denotes the index number of the $i^{\text {th }}$ sub-area in the control plane. In the calculations, the contaminant plume was assumed to discharge only from the north stream bank, as indicated by results from the concentration measurements at Transect 2 (Figure 2). The control plane, CP1, ran perpendicular to the long axis of the plume (Figure 1D) for a distance of $84 \mathrm{~m}$ beside the stream, and vertically from the approximate elevation of the groundwater table (34 m asl corresponding to ca. 0.2-1.2 mbgs, as of Oct. 2014) downward 9 $\mathrm{m}$ (25 $\mathrm{m}$ asl). The control plane was actually curved to remain paral lel to a meander in the stream channel, but was treated as a straight rectangular area of $756 \mathrm{~m}^{2}$ for the purposes of the contaminant mass discharge calculations.

A concentration grid in CP1 was obtained from ordinary kriging using the gstat package in R software (v3.3.1). An exponential variogram model (fitted to the concentration data) was applied and an anisotropy factor of 10 and a cell size of $10 \times 10 \mathrm{~cm}^{2}$ were used. Other concentration grids were considered (see SI Figure S4), however, the choice of grid did not influence the result considerably. The concentration grid was combined with two estimates of specific discharge obtained by:

1) Darcy's law, using the geometric mean of the hydraulic conductivity $(K)$, which is commonly assumed to be representative for the average hydraulic conductivity in an aquifer (Béland-Pelletier et al., 2011; Chapman et al., 2007; Kempf et al., 2013), derived from mini-slug tests and a gradient measured at the groundwater-surface water interface at Transect 2 (Figure 2). In fact, the gradient in the horizontal 
direction and perpendicular to CP1 (termed the normal gradient) was estimated, which is needed in the calculation of contaminant mass discharge (Basu et al., 2006; ITRC, 2010). The normal gradient was estimated based on hydraulic head values in three points downgradient from CP1 (Figure 2) (no hydraulic head data upgradient from CP1 was available). The obtained value was in accordance with the hydraulic head contour lines in Figure 2 and thus thought to be reasonable. Correction for the flow angle was conducted using:

$$
\frac{\overline{d H}}{d x}=\cos (\beta) \cdot \frac{d H}{d x}
$$

(Equation 2)

where $\frac{\overline{d H}}{d x}$ is the normal gradient, $\frac{d H}{d x}$ is the gradient, and $\beta$ is the vertical flow angle in radians. The contaminant mass discharge obtained by using this method for specific discharge estimation was termed $J_{C P, D a r c y}$.

2) Direct groundwater velocity measurements from PVPs. As for the Darcy-based method described above, the flow component perpendicular to CP1 is needed, hence the seepage velocity perpendicular to the control plane (termed the normal seepage velocity) was calculated for each PVP injection test conducted on the north bank, using:

$$
\bar{v}=\sqrt{\left(v_{h} \sin \left(\beta_{h}\right)\right)^{2}+\left(v_{v} \cos \left(\beta_{v}\right)\right)^{2}}
$$

(Equation 3)

where $\bar{v}$ is the normal seepage velocity, $v_{h}$ and $v_{v}$ are the horizontal and vertical seepage velocities, and $\beta_{h}$ and $\beta_{v}$ are the angles in radians between the curved control plane and the horizontal and vertical groundwaterflow directions, respectively. However, since the control plane is not tilted, we need only to consider the horizontal velocity component and Equation 3 can be reduced to:

$$
\bar{v}=v_{h} \sin \left(\beta_{h}\right)
$$

(Equation 4)

Hereafter, the specific discharge was obtained by multiplying by the porosity (0.37). From the PVP data, two different grids of specific discharge were created:

a) A constant value covering the entire grid equal to the weighted mean of all normal specific discharge values calculated. The weights were chosen so that each PVP was weighted equally, irrespective of the number of injections conducted at the individual PVPs. The contaminant mass discharge obtained by using this method for specific discharge estimation was termed $J_{C P, P V P m e a n}$. 
b) A non-regular grid consisting of squared cells based on the location of PVPs. Each cell was assigned a specific discharge equal to the average value of the PVP within the cell (SI Figure S5). The contaminant mass discharge obtained by using this method for specific discharge estimation was termed $J_{C P, P V P \text { vary }}$.

\subsection{In-stream contaminant mass discharge}

The in-stream contaminant mass discharge was obtained from a relationship between the completely mixed stream concentrations $\left(c_{\text {mix }}\right)$ and corresponding stream discharge $\left(Q_{\text {mix }}\right)$. The point of complete mixing is defined as the location downstream of the contaminant source at which the stream water concentrations along a transverse transect across the stream are within $5 \%$ of the mean value within the transect (Fischer et al., 1979). The distance from a discharging point source $(x=0)$ to the point of complete mixing is called the mixing length $\left(L_{m i x}\right)$.

Ignoring attenuation processes other than dilution, and assuming no accumulation of contaminant mass between a discharging point source and $x=L_{\text {mix }}$, the total contaminant mass discharge added to the stream by the point source $\left(J_{\text {input }}\right)$ can be derived from the flux balance:

$$
J_{\text {upstream }}+J_{\text {input }}=c_{\text {mix }} Q_{\text {mix }}
$$

(Equation 5)

where $J_{\text {upstream }}$ is the in-stream contaminant mass discharge at $x=0$. Through model simulations of Grindsted stream, Aisopou et al. (2015) found that volatization plays a minor role along such a short stream reach, such as the one investigated, likely due to the relatively large stream depth. Furthermore, if the sum of chlorinated ethenes (expressed as PCE eq) is considered rather than the individual compounds, then the error due to dechlorination of PCE to TCE, TCE to DCE, and DCE to vinyl chloride is eliminated. Equation 5 is therefore considered to be valid for the investigated stream reach and can be rewritten as:

$$
c_{\text {mix }}=J_{\text {mix }} / Q_{\text {mix }}
$$

(Equation 6)

where $J_{\text {mix }}$ is the total contaminant mass discharge at $x=L_{\text {mix }}$, i.e. the sum of $J_{\text {upstream }}$ and $J_{\text {input }}$. Since no gauging station was located at $x=L_{\text {mix }}, Q_{\text {mix }}$ was estimated from measurements at the nearby gauging stations up- and downstream of the focus area, respectively, assuming a linear increase in stream discharge with increasing downstream distance following the course of the stream. A second approach for stream discharge estimation 
was carried out, in which linear interpolation was conducted along two straight lines following the overall course of the stream between the two gaining stations. The two methods yielded the same results for $J_{\text {mix }}$.

To test whether a correlation between $c_{\text {mix }}$ and $Q_{\text {mix }}$ existed, as suggested in Equation 6, the null hypothesis, i.e. no relationship between $c_{\text {mix }}$ and $Q_{\text {mix }}$, was tested using an F-test (linear regression, $\alpha=0.05$ ). This test was conducted for cis-DCE and vinyl chloride, since these compounds were detected in all sampling campaigns, as well as for the total chlorinated ethenes.

After rejection of the null hypothesis, $J_{\text {mix }}$ for total chlorinated ethenes, cis-DCE and vinyl chloride was obtained by fitting Equation 6 to experimentally measured values of $c_{\text {mix }}$ and $Q_{\text {mix }}$, assuming $J_{\text {mix }}$ was constant.

Having quantified $J_{\text {mix }}$, the flux balance can be expanded to permit calculation of groundwater-borne in-stream contaminant mass discharge, which could be directly compared to $J_{C P}$ from Equation 1 . Specifically, $J_{\text {mix }}$ was corrected for the $J_{\text {upstream, }}$ as well as for the contaminant mass discharge contribution from the culverts:

$$
J_{G W}=J_{\text {mix }}-J_{\text {upstream }}-J_{\text {culverts }}
$$

(Equation 7)

where $J_{G W}$ is the in-stream contaminant mass discharge contribution from groundwater, and $J_{\text {culverts }}$ is the contaminant mass discharge contribution from the culverts $\left(J_{\text {culverts }}=c_{\text {culverts }} Q_{\text {culverts }}\right)$.

\section{Results}

\subsection{Contaminant transport from aquifer to stream}

The hydraulic head and chlorinated ethene concentrations measured at Transect 2 (Figure 1D) have been contoured in Figure 2. A normal gradient at the north bank of 0.034 was estimated (see section 4.1). Although temporal variations are expected, hydraulic head measurements conducted a few meters further downstream in May 2014 (Rønde, 2014) also indicated that groundwater was flowing to the stream with a similar hydraulic gradient. 


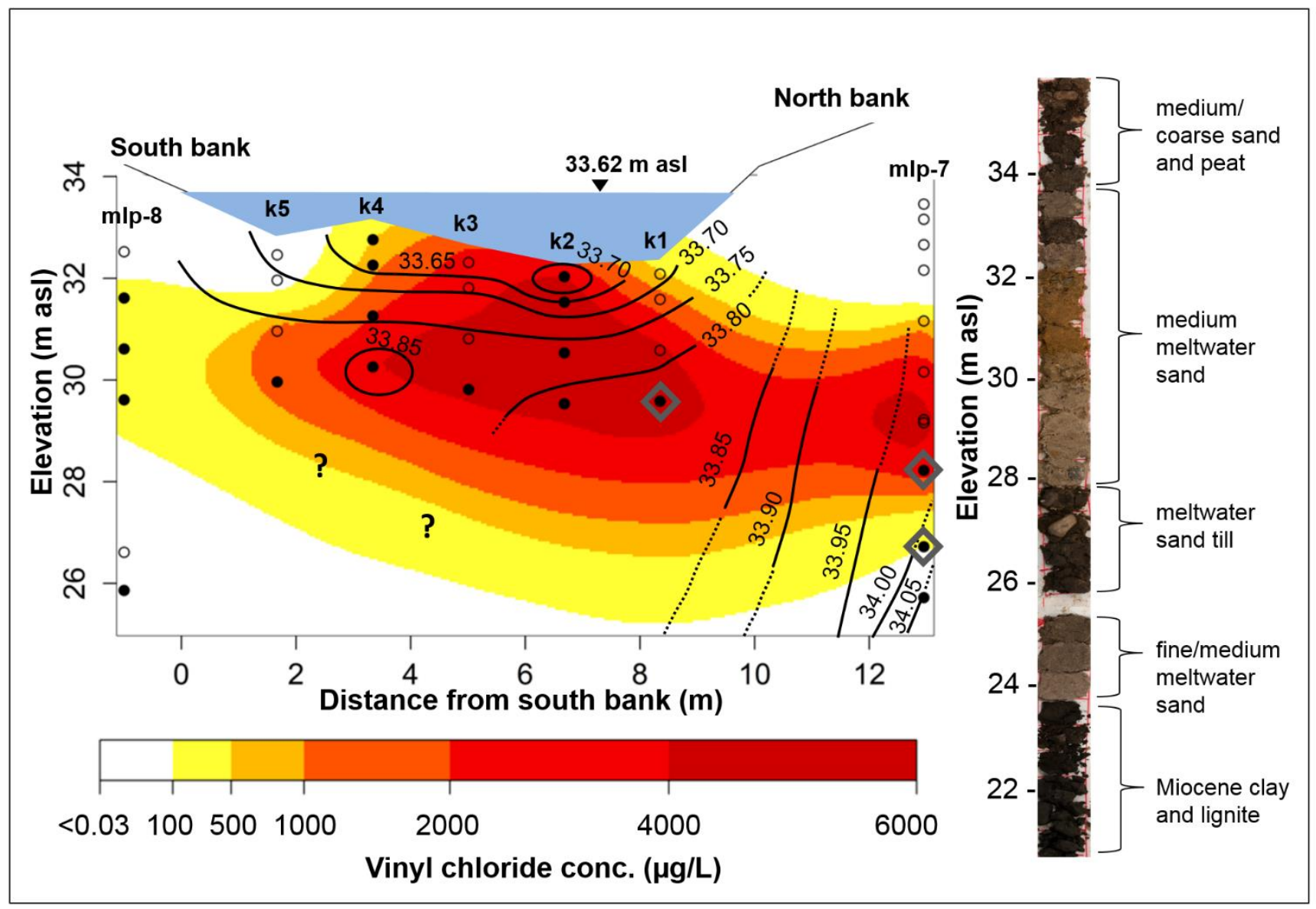

Figure 2: Transverse profile across the stream at Transect 2 (see also Figure 1D) showing the viny/chloride concentration (colored contour) and the hydraulic head in $\mathrm{m}$ asl (line contour; the dotted lines indicate high uncertainty due to sparse data). The flow field was inferred considering both hydraulic head measurements and the concentration contours. The circles indicate locations of data points at which hydraulic head (filled) and chemical concentrations (open and filled) were measured. The bore log is from well 114. 2507 (Figure 1D). The dark grey diamonds indicate data points that were used to calculate the normal gradient.

Measurements of vinyl chloride concentrations in Transect 2 show that a plume containing high concentrations discharges from the north to the stream through almost the entire width of the streambed (Figure 2). A similar picture was seen for cis-DCE (data not shown). Lower streambed concentrations were measured in several locations a few meters up- and downstream of Transect 2 (SI Figure S6), indicating that the core of the plume is entering the stream at or close to Transect 2 (Figure 1D). This is confirmed by the concentration measurements of chlorinated ethenes in CP1, which show that the core of the plume (ca. $50 \mathrm{~m}$ in length), embedded within a 
larger plume, is discharging to the stream with the highest concentrations at mlp-7, i.e. Transect 2 (Figure 3). cis-DCE and vinyl chloride were by far the dominant constituents of the chlorinated ethenes in the groundwater, with concentrations exceeding $5,000 \mu \mathrm{g} / \mathrm{L}$ in some locations. In contrast, the concentrations of PCE and TCE were considerably lower (maximum 186 and $67 \mu \mathrm{g} / \mathrm{L}$, respectively). Additional chemical characterization of the plume (SI Table S2) from boreholes 114.2507 and 114.2508 (Figure 1D) immediately upgradient of the core of the plume showed similar chemical composition of chlorinated ethenes. The high fraction of degradation products indicates that dechlorination is occurring in the aquifer upgradient of CP1.

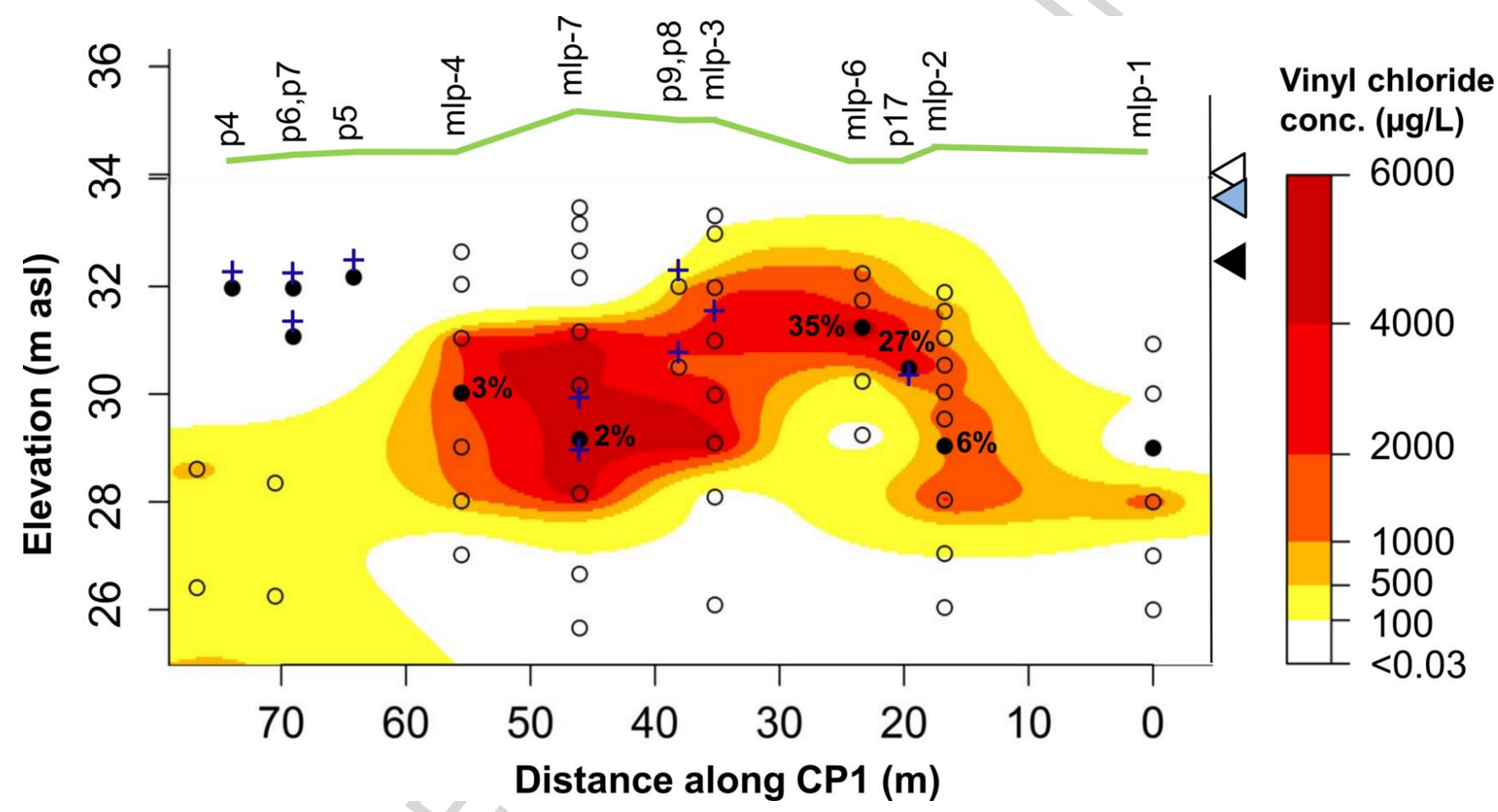

Figure 3: Vinyl chloride concentrations in groundwater measured in wells along the control plane, CP1 (Figure 1D). The distance shown on the $x$-axis is the distance along CP1 from the well mlp-1. Open and filled circles indicate data points sampled once and twice, respectively. For overlapping samples in the plume core, the deviation from the mean is indicated in percentage. Blue crosses indicate locations of installed PVPs (Figure 1C). The white, blue and black triangles (right y-axis) indicate the approximate groundwatertable, the stream level as of May 2015, and streambed elevation, respectively. The green curvature represents the terrain level.

\subsection{Hydraulic conductivity}


The core of the plume is found within a medium-grained meltwater sand layer (Figure 2) at ca. $28-31 \mathrm{~m}$ asl. At this elevation range, the geometric mean of $K$ was $1.8 \times 10^{-4} \mathrm{~m} / \mathrm{s}$ and the variance in $\ln K\left(\sigma^{2} \ln K\right)$ was 0.56 , suggesting high permeability and mild heterogeneity $\left(\sigma^{2} \ln K<1\right.$, Bohling et al., 2012). The sand layer is underlain by a layer of meltwater sand till (Figure 2) with a geometric mean $K$ value of $6.4 \times 10^{-5} \mathrm{~m} / \mathrm{s}$ and a $\sigma^{2} \ln K$ of 4.45 , suggesting lower permeability and moderate to high heterogeneity $\left(\sigma^{2} \ln K>2\right.$, Bohling et al., 2012). In this layer relatively low chlorinated ethene concentrations are found. Since the chlorinated ethenes are easily transported with water due to their relatively high solubility and low octanol-water partitioning coefficient, the highest concentrations are expected to be found in the high permeability layer. Hence, the pattern of contaminant concentrations agrees well with expectations based on the geology. This underscores the importance of adequately characterizing the geological framework to gain insights relevant to contaminant transport.

The distribution of hydraulic conductivity is shown in Figure 4 along with the outlines of the cis-DCE and vinyl chloride plume cores. Since the plume cores are mainly located at $28-31 \mathrm{~m}$ asl, we find it reasonable to use the geometric mean of $K$ for this elevation range in the Darcy-based mass discharge calculation. To support this decision, the contaminant mass passing through CP1 at $28-31 \mathrm{~m}$ asl using the geometric mean $K$ value for this elevation range $\left(1.8 \times 10^{-4} \mathrm{~m} / \mathrm{s}\right)$ was compared with the contaminant mass passing through the entire CP1(25 $34 \mathrm{~m}$ asl) using a $K$ value equal to the geometric mean for the entire control plane $\left(1.1 \times 10^{-4} \mathrm{~m} / \mathrm{s}\right)$. A lower contaminant mass discharge was obtained for the entire CP1, suggesting that the contaminant mass discharge will be underestimated if a geometric mean of $K$ for the entire CP 1 is used. This has important implications for the level of detail needed in characterizing $K$ at sites; single, large-scale values are likely to introduce biases to mass discharge estimations. 


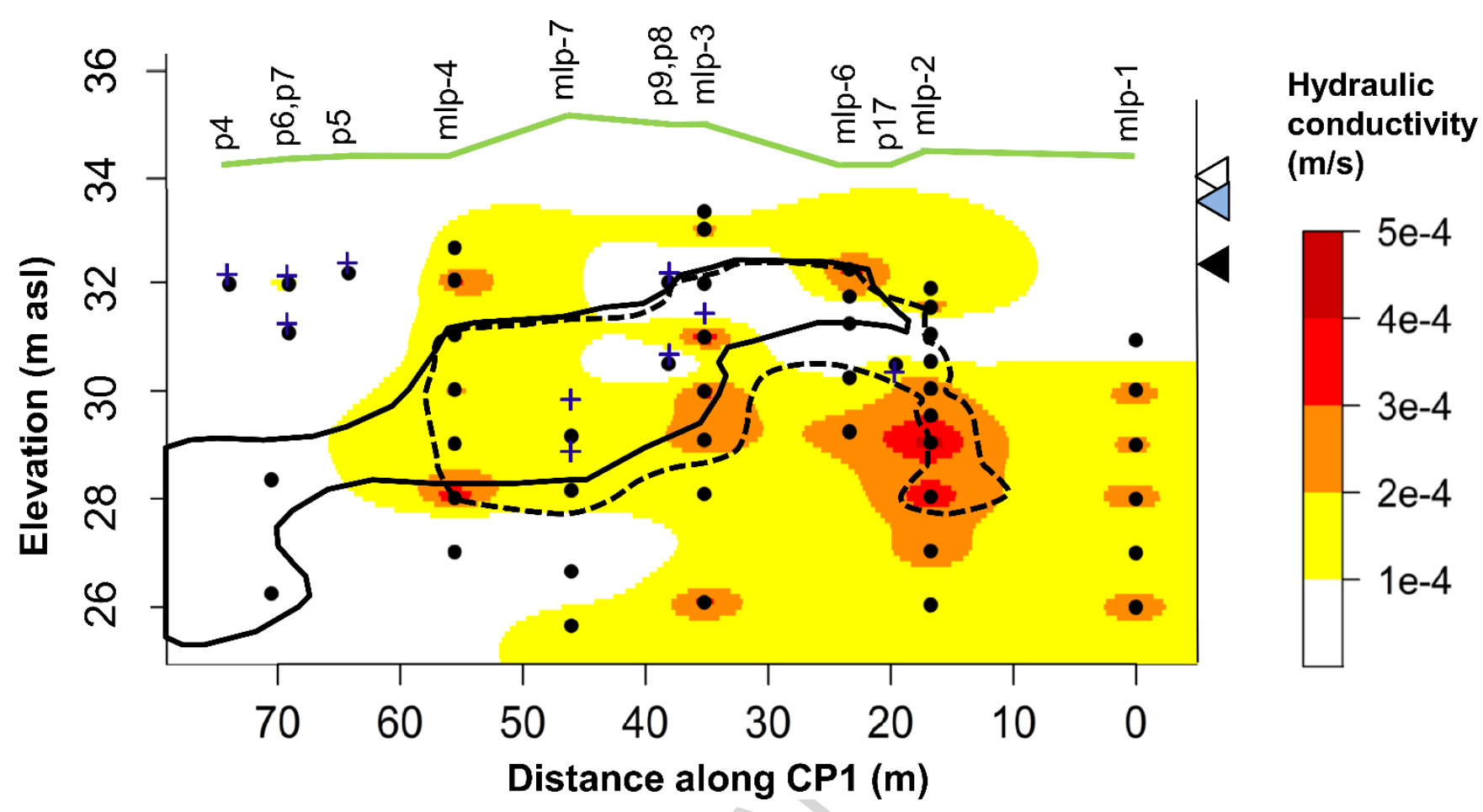

Figure 4: Distribution of hydraulic conductivity along CP1 (Figure 1D). The black circles indicate hydraulic conductivity measurements, while the blue crosses indicate locations of installed PVPs (Figure 1C). The solid and dashed contours indicate the $1000 \mu \mathrm{g} / \mathrm{L}$ isopotential line for cis-DCE and vinyl chloride, respectively. The white, blue and black triangles (righty-axis) indicate the approximate groundwater table, the stream level (May 2015) and streambed elevation, respectively.

\subsection{Groundwatervelocity and flow direction from PVPs}

A remarkable feature of the PVP is its ability to separate the horizontal and vertical flow components (as listed in SI Table S3). This is an advantage when quantifying the contaminant mass discharge because most often the investigated control plane is not exactly perpendicular to the flow direction. In addition, the flow direction might vary along the control plane. The flow angles can be used to determine the velocity component perpendicular to the control plane, as required for determination of the contaminant mass discharge (Equations 3 and 4). In this case, only the horizontal flow component is required in the contaminant mass discharge calculation, hence details on vertical flow are provided in the SI (i.e. Figure S7 and corresponding text). 
Results from 89 PVP injection tests showed that groundwater flowed towards the stream (Figure 1C), consistent with trends in hydraulic head (Figure 1A and Figure 2). Based on data from all PVPs (located on both sides of the stream), the standard deviation in the horizontal flow direction for each PVP was generally very low: for 7 out of the 11 functioning PVPs, it was below $11^{\circ}$ while for the remaining 4 PVPs it was maximum $35^{\circ}$. These results indicate that the PVP is able to measure the horizontal flow direction close to streams with rather high precision. This is supported by laboratory tests conducted by Labaky et al. (2007) where the flow direction was determined within $8^{\circ}$ based on 10 injection tests. Devlin (2016) showed that this level of uncertainty in flow directions is the minimum expected, based on a sensitivity analysis of the PVP equations. Variability greater than this suggests causes related to physical factors in the flow system. Regardless, the current results indicate that the temporal variation in the horizontal groundwater flow direction was small during the measurement period.

The mean seepage velocity was calculated for each PVP based on multiple tests conducted at different times. The resulting values ranged from $0.1 \mathrm{~m} / \mathrm{d}$ (PVP9) to $2.5 \mathrm{~m} / \mathrm{d}$ (PVP16), reflecting a high spatial variability. The maximum standard deviation was $60 \%$ (PVP20). The high standard deviation is not surprising since high temporal variations in the seepage velocity are expected close to streams and rivers.

No clear correlation between hydraulic conductivity and PVP velocity (both total and horizontal components) was found. The lack of correlation suggests a spatial variation in the gradient across CP1. Correlation with ground water concentrations of chlorinated ethenes was likewise lacking, thus such relationships could not be used to estimate seepage velocities in locations with no PVPs.

The mean normal seepage velocity along CP1 is shown in Figure 5. It ranged from $0.04 \mathrm{~m} / \mathrm{d}$ (PVP9) to $2.0 \mathrm{~m} / \mathrm{d}$ (PVP18) with a weighted mean of $0.8 \mathrm{~m} / \mathrm{d}$. Results and details from all PVP injection tests can be found in SI Table S3. 


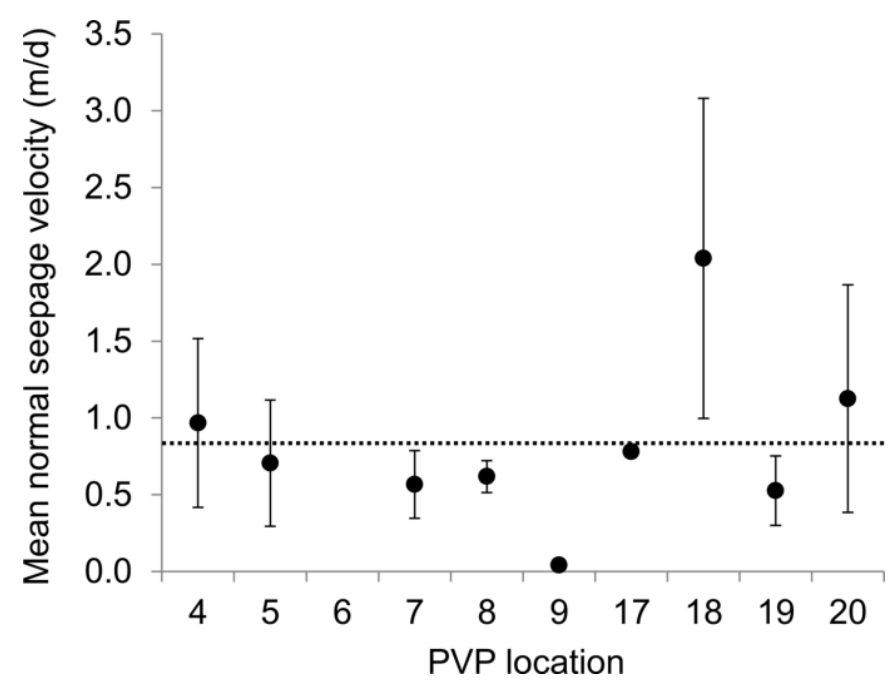

Figure 5: The mean of the normal seepage velocity (filled circles) calculated for each of the PVPsfrom Nov. 2013 to Nov. 2015 at the north bank. The error bars indicate \pm 1 standard deviation. The dotted line indicates the weighted mean of the normal seepage velocity obtained from the individual injection tests on the north bank.

\subsection{Contaminant mass discharge at the stream bank (CP1)}

The Darcy-based method for specific discharge estimation yielded a result of $0.32 \mathrm{~m} / \mathrm{d}$, resu lting in a mass discharge $\left(J_{C P, \text { Darcy }}\right)$ of $372 \mathrm{~kg} / \mathrm{y}$ (PCE eq.) The PVP-based methods yielded a mean specific discharge of $0.29 \mathrm{~m} / \mathrm{d}$ and a specific discharge field shown in SI Figure S5, resulting in contaminant mass discharges of 204 and 269 $\mathrm{kg} / \mathrm{y}\left(\right.$ PCE eq), for $J_{C P, P V P m e a n}$ and $J_{C P, P V P V a r y}$, respectively. Contaminant mass discharge values for the different chlorinated ethenes can be found in Table 1. 
Table 1: Contaminant mass discharges for the in-stream and control plane approach. Values for $J_{G W,} J_{C P, D a r c y}$ $J_{C P, P V P m e a n}$ and $J_{C P, P V P V a r y}($ bold font) are the estimates of the groundwater-borne contaminant mass discharge and can thus becompared.

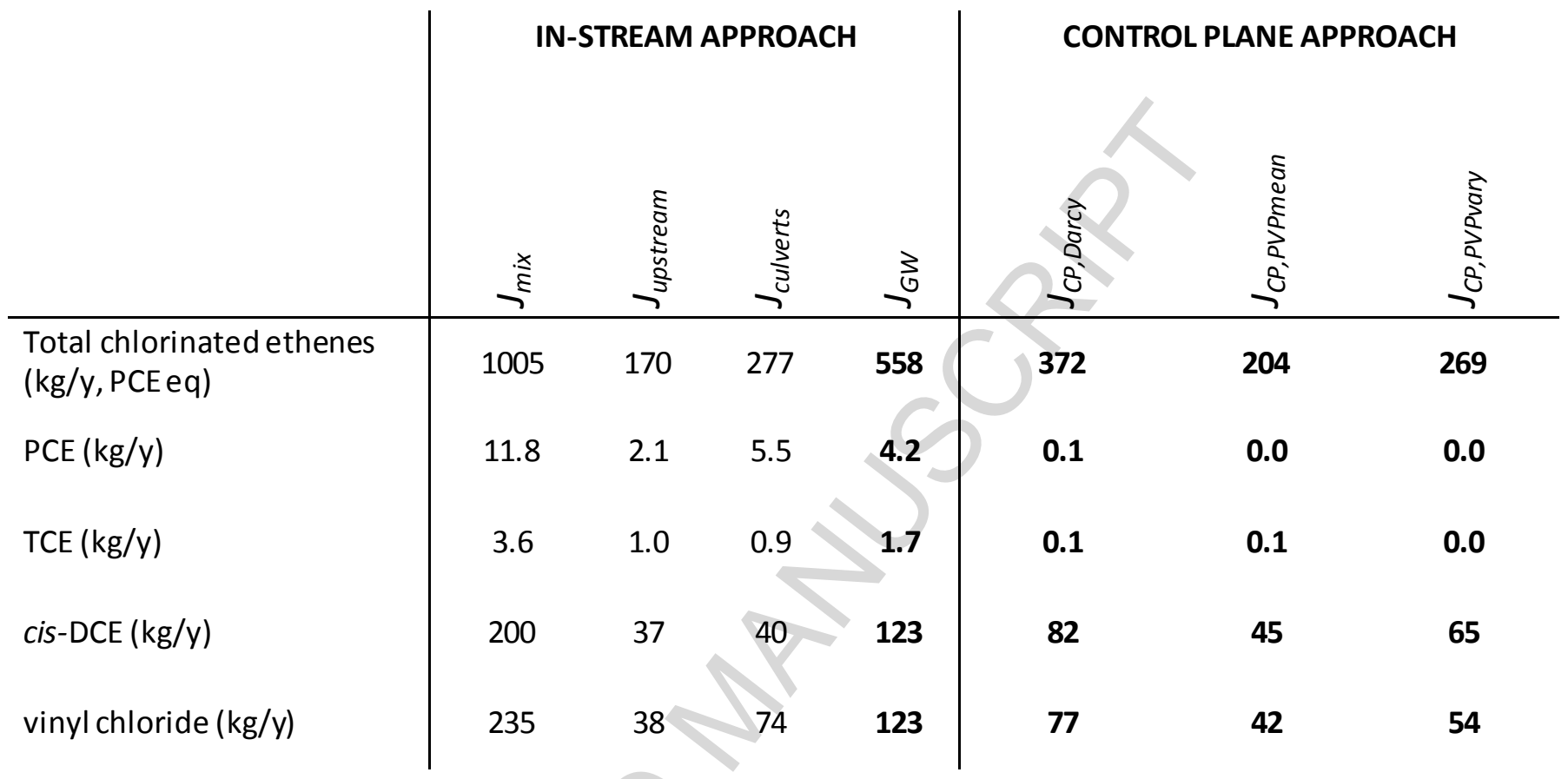

\subsection{In-stream contaminant mass discharge}

\subsubsection{Determining the point of completely mixed conditions $\left(x=L_{\text {mix }}\right)$}

Before estimating the contaminant mass discharge $\left(J_{\text {mix }}\right)$ at $x=L_{\text {mix }}$ from Equation 6 , the location $x=L_{\text {mix }}$ had to be determined. This was done by evaluating the variation in contaminant concentrations (mid-depth) along 6 transverse transects across the stream channel (Figure 6). The temporal variation in the horizontal distribution was minor, except at transects 2 and 3. A tendency for higher concentrations of chlorinated ethenes to occur in the middle and north side of the stream was observed at Transects 1-5 (Figure 6). This supports the notion that the plume of chlorinated ethenes enters the stream primarily from the north, as previously shown in Figure 2. In contrast, at the most downstream transect (Transect 6) the concentration gradient across the stream was low: in May 2014 and Oct. 2014 the stream water concentrations were within 2 and 6\% of the mean, respectively. Therefore, Transect 6 was assumed, for practical purposes, to be the point of complete mixing $\left(x=L_{\text {mix }}\right)$, although slightly above the variation limit of $5 \%$ proposed by Fischer et al. (1979) in the Oct. campaign. 
Vinyl chloride and cis-DCE were found in the highest concentrations, while PCE and TCE (data not shown) occurred at much lower levels.

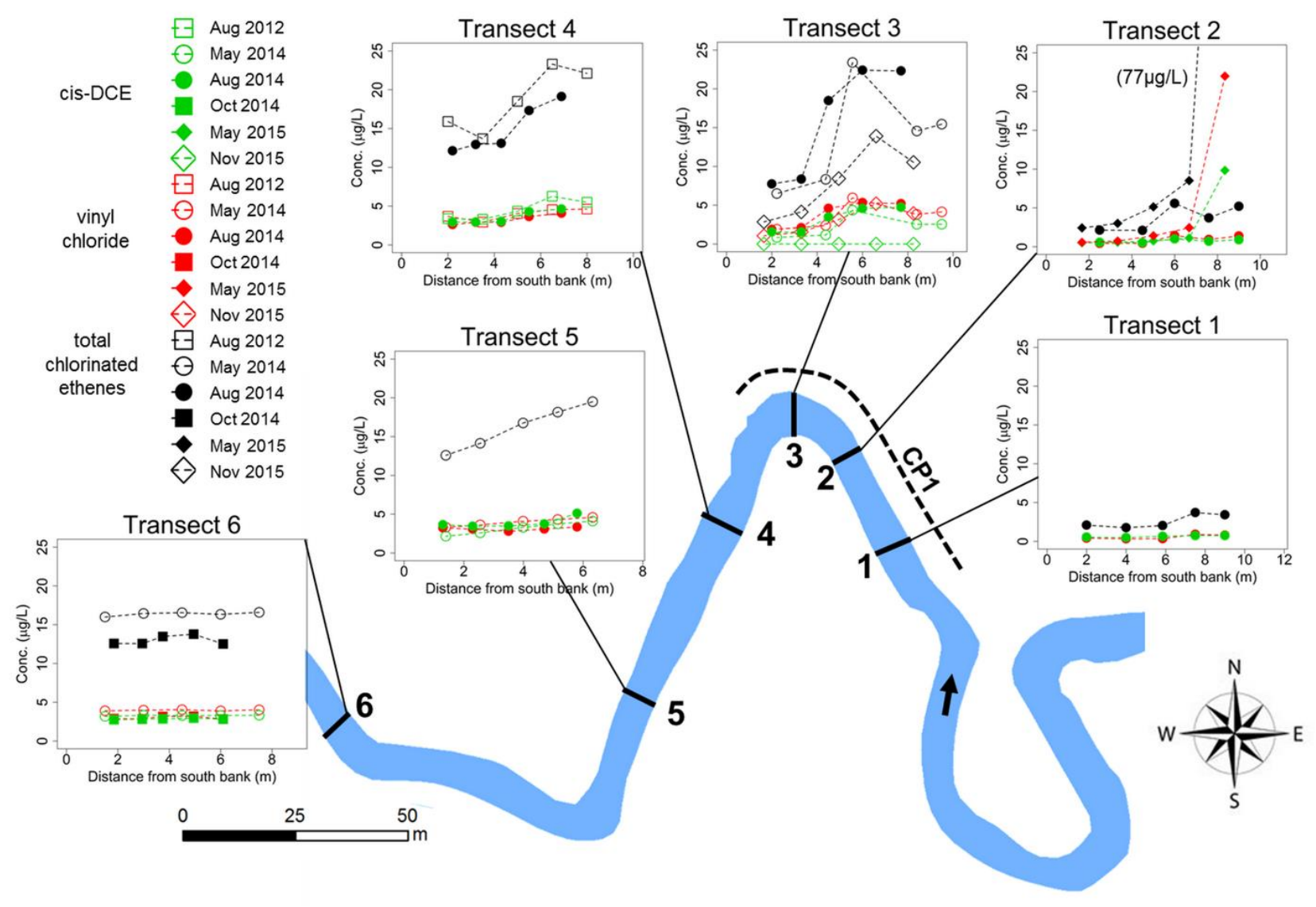

Figure 6: Concentrations of totalchlorinated ethenes (black), cis-DCE (green) and vinylchloride (red) in transverse transects across the stream. In transect 2, the concentration of total chlorinated ethenes measured closest to the north bank in May 2015 was 77 Mg/L (data point outside the shown concentration range).

\subsubsection{Determination of the in-stream contaminant mass discharge}

The parameter $J_{\text {mix }}$ was obtained by fitting Equation 6 to a scatterplot of $c_{\text {mix }}$ versus $1 / Q_{\text {mix }}$ using data from Transect 6. Good fits were observed for total chlorinated ethenes, cis-DCE and vinyl chloride with $\mathrm{R}^{2}$ values of $0.86,0.59$ and 0.77 , respectively (Figure 7). The higher $R^{2}$ value for the total chlorinated ethenes is expected, as it minimizes variations in $J_{\text {mix }}$ that may be caused by temporal variations in reductive dechlorination, e.g. due to a transient hyporheic mixing zone (Freitas et al., 2015). These good fits indicate that $J_{\text {mix }}$ is not greatly 
influenced by the stream discharge and thus varies little in time. This also points to a relatively constant contaminant mass discharge at the stream bank; hence its quantification using data collected over two years can be justified. For the total chlorinated ethenes, $J_{\text {mix }}$ was estimated to $1005 \mathrm{~kg} / \mathrm{y}$ (Figure $7 \mathrm{~A}$ ), while $J_{G W}$ was calculated from Equation 7 to be $558 \mathrm{~kg} / \mathrm{y}$ (PCE eq) (Table 1).

\section{A Total chlorinated ethenes}

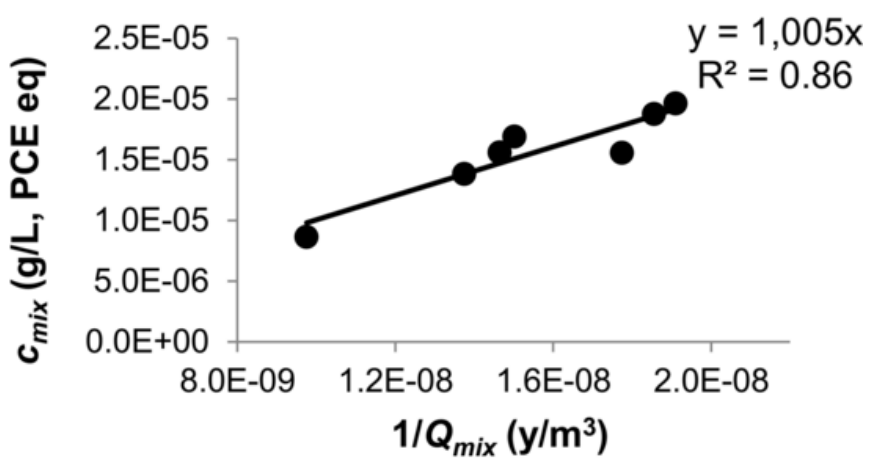

B cis-DCE
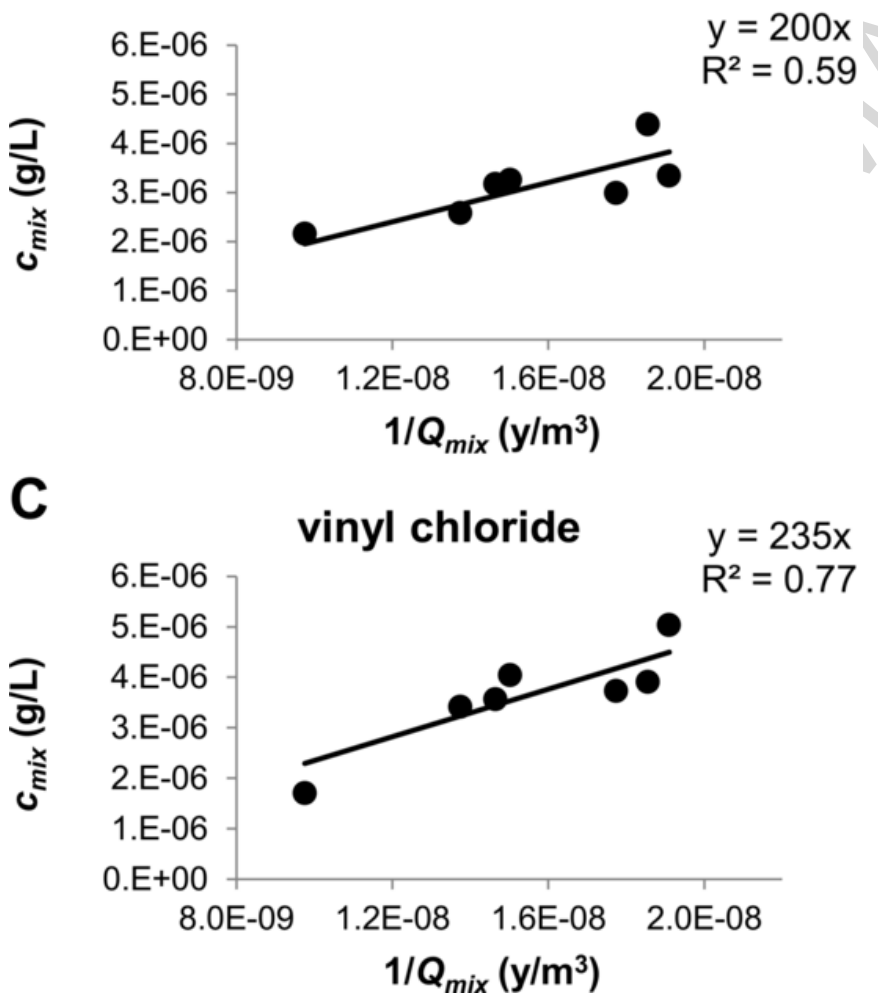

Figure 7: $c_{\text {mix }}$ of $A$ ) total chlorinated ethenes, B) cis-DCE and C) vinyl chloride versus $1 / Q_{\text {mix. }}$ The trend lines are linear regression models fitted to the data. The slopes of the lines thus represent $J_{\text {mix }}$ in $\mathrm{kg} / \mathrm{y}$. 


\section{Discussion}

The contaminant mass discharge estimates at the stream bank, $J_{C P}$, were all lower than the estimate of the instream value, $J_{G W},\left(67 \%, 37 \%\right.$ and $48 \%$ of the in-stream value for $J_{C P, D a r C y} J_{C P, P V P \text { mean }}$ and $J_{C P, P V P v a r y}$, respectively). The experimental data can therefore be explained either as an underestimation of $J_{C P}$ or an overestimation of $J_{G W}$.

Several factors may lead to uncertainty in the contaminant mass discharge estimates at the stream bank and in the stream: 1) high concentration zones within the control plane might have been missed;2) contaminant mass may have by-passed the control plane; 3) regarding the Darcy-based method, the uncertainty in hydraulic conductivity values is high and the normal gradient may not have been representative for the entire control plane; 4) PVPs may not have been placed in the fastest zones of the aquifer and/or high concentration zones may have been located in faster flow conduits than were tested with the PVPs; 5) discharge from the culverts may have been underestimated; 6) attenuation processes may have led to the loss of contaminant mass between the stream bank and $x=L_{\text {mix }}$; and finally 7) uncertainty in $c_{\text {mix }}$ and $Q_{\text {mix }}$ has led to uncertainty in $J_{\text {mix }}$. These possibilities are discussed in more detail below.

\subsection{Uncertainty in $J_{C P}$}

The possibility that high concentration zones located within the control plane were missed would have led to an underestimation of $J_{C P}$ at the stream bank. At a site with a moderate heterogeneity, Troldborg et al. (2012) found a sampling density of 0.1 point $/ \mathrm{m}^{2}$ to be sufficient to obtain a contaminant mass discharge estimate with a relative uncertainty $<50 \%$ in a plume of comparable size to the one at our study site. In this study the sampling density was slightlylower $\left(0.08\right.$ points $\left./ \mathrm{m}^{2}\right)$. Considering also the geology in CP1, which is mildly heterogeneous in some parts and moderately-to-highly heterogeneous in others, we can expect an uncertainty in $J_{C P}$ of $>50 \%$.

Contaminant mass may also have by-passed the control plane entirely, if the plume was not fully delineated or if multiple plumes exist. Contamination may, for example, enter the stream from the south bank, however, the stream water concentrations observed in the transects across the stream (Figure 6) indicate that the majority of contaminant mass enters the stream from the north bank between Transects 1 and 3, where the control plane is located. Some contamination could also enter the stream further downstream of the control plane, as indicated by the cis-DCE plume, which has not been fully delineated (SI Figure S3). Both stre ambed (SI Figure 
S6) and stream water (Figure 6) concentrations indicate, however, that only minor input entered the stream downstream of the control plane. Another possibility is that contaminant mass is discharging into the stream from the deeper parts of the aquifer, i.e. bypassing the control plane from below. Since concentration data are lacking for depths $>3 \mathrm{~m}$ below the streambed at Transect 2 ( Figure 2), this possibility cannot be dismissed.

The high uncertainty associated with hydraulic conductivity estimates may have led to an underestimation of the specific discharge for the Darcy-based method, producing an underestimation of the contaminant mass discharge from this method. Reliable estimates of the hydraulic conductivity remain a challenge, partly because large spatial variations in geology over small distances exist and partly because of issues regarding the size of a representative element volume, i.e. the obtained results depend on the scale investigated (Rovey and Cherkauer, 1995). This source of uncertainty is well known for Darcy-based methods of calculating mass discharges in aquifers, and is one of the motivating factors for assessing alternative, complementary and independent methods.

Another source of error in the Darcy-calculated contaminant mass discharge may come from the normal gradient used, which may not have been representative of the conditions at CP1, due to the multi-directional groundwater flow field close to streams (Freitas et al., 2015; Kasahara and Hill, 2007; Keery et al., 2007; Storey, 2003). Indeed, the lack of correlation between seepage velocity and hydraulic conductivity points to a spatially varying gradient across CP1. Moreover, representative values of the gradient over short distances such as in Transect 2 (Figure 2) are difficult to measure (Silliman and Mantz, 2000).

The PVP-based method could have underestimated the water flux through the control plane if the PVPs were not placed in the fastest zones of the aquifer. Also, regarding the $J_{C P, P V P m e a n}$, it was not considered that high concentration zones may be located in fast flow conduits, which is likely the reason for the lowervalue of $J_{C P, P V P m e a n}$ compared to $J_{C P, P V P v a r y}$. Finally, one could argue that all flow crossing CP1 ends up in the stream, even if it does not - at the centimeter scale at which the PVP operates - cross the control plane at right angles. This would mean that the PVP-based contaminant mass discharges are underestimated by the factor $\sin \left(\beta_{h}\right)$, c.f. Equation 4.

Generally, an increase in the density of data points would decrease the uncertainty in $J_{C P}$. For example, to minimize the risk of missing high concentration zones, additional concentration measurements within the control plane would be required, whereas to confirm or rule out that contaminant mass by-passes the control plane, additional concentration measurements outside of the control plane would be needed, i.e. at the north 
and south banks and $>3 \mathrm{~m}$ below the streambed. Moreover, the uncertainty of the normal gradient could be decreased by additional hydraulic head measurements, preferably at multi-level depths below the streambed and at the bank along several transects across the stream, as well as immediately upgradient of the control plane. Finally, the uncertainty in the PVP-derived velocity field could be decreased by installing additional PVPs and/or distributing them more evenly across the control plane.

\subsection{Uncertainty in $J_{G W}$}

Regarding $J_{G W}$, an important source of uncertainty might arise from the estimation of contaminant mass discharge from the culverts. The contaminant concentration and discharge in the culverts were only measured twice. Since the contaminant input from the culverts constitutes ca. $28 \%$ of $J_{m i x}$, an error in this input value would considerably affect the ground water-borne in-stream contaminant mass discharge, $J_{G w}$. The slightly larger fraction of PCE and vinyl chloride for $J_{G W}$ compared to the estimates at the stream bank $\left(J_{C P}\right)$ (Figure 8), suggests that there was additional input to the stream with higher PCE and vinyl chloride concentrations. Since water from the culverts differs in chlorinated ethene composition compared to other inputs, with a higher ratio of both PCE and vinyl chloride, there is reason to believe that the input from the culverts has been underestimated. Moreover, the culverts may have collected contaminated groundwater through leaky joints along the length of the culvert, between the inlet and the outlet at the stream, and thus have contributed more contaminant mass than measured at the culvert inlet.

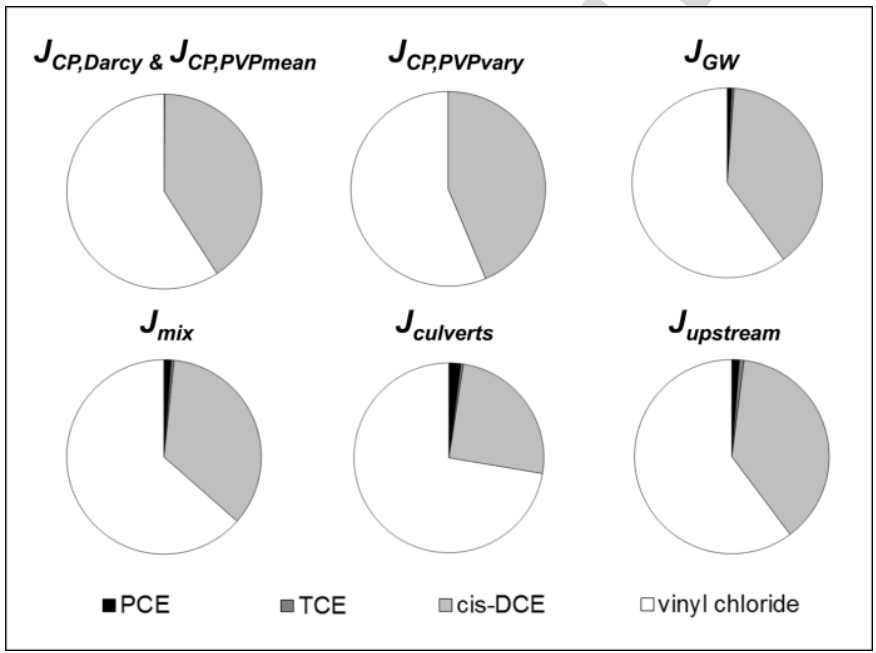

Figure 8: Molar distributions of PCE, TCE, cis-DCE and vinylchloride for $J_{C P}, J_{G W}, J_{\text {mix }} J_{\text {culverts }}$ and $J_{\text {upstream. }}$. 
Attenuation processes such as sorption-desorption and back-diffusion are not expected to play a major role, due to the low octanol-water partition coefficient of the chlorinated ethenes and the sandy geology (low organic carbon content on the sediments (Sonne et al., 2017)) at the site. If attenuation processes such as dechlorination, photo-oxidation or volatilization were important, contaminant mass losses would have occurred between CP1 and $x=L_{m i x}$, leading to an underestimation of $J_{G W}$. Since $J_{G W}$ was higher than $J_{C P}$ irrespective of the specific discharge field used, there is little support in the data for this scenario. Also, the consistency of the molar ratios between PCE, TCE, cis-DCE and vinyl chloride in the aquifer and stream water seems to suggest that degradation plays a minor role (Figure 8). In addition, the residence time of the stream water in the study area is extremely short; hence detectable losses due to attenuation processes in the stream water are not expected. Some dechlorination might occur in the streambed, but since high concentrations of degradation products are observed in CP1, we expect that the main degradation occurs in the aquifer upgradient of CP1.

Contrasting observations were made by Conant et al. (2004) who observed extensive degradation within the top $2.5 \mathrm{~m}$ of the streambed for a PCE plume discharging to the Angus River in Canada, and Lorah and Olsen (1999) who demonstrated the potential for effici ent natural attenuation of chlorinated organic compounds at the groundwater-surface water interface under reduced conditions. However, Weatherillet al. (2014) and Ellis and Rivett, (2007) did not observe extensive streambed degradation of chlorinated volatile organic carbons (VOC), while Lee et al. (2015) saw dechlorination of a TCE plume to VC before it entered the Wonju stream in Seoul, Korea. Freitas et al. (2015) identified three streambed reaches exhibiting different degradation behaviors: extensive dechlorination due to surface water mixing into the streambed; absence of dechlorination caused by an absence of the hyporheic zone; and a sporadic dechlorination attributed to a locally complex geology. The minor degree of dechlorination in the streambed at our study site may be due to a thin hyporheic zone that may be suppressed by high groundwater inflow ( Figure 2), as suggested by Freitas et al. (2015). Similarly, Abe et al. (2009) observed a reverse relationship between dechlorination and flow velocities at the Angus River, and only modest dechlorination in high flow velocity zones with low residence time. Further investigations are required, however, to fully understand the role of the hyporheic zone and attenuation processes at the study site.

Uncertainty in $Q_{\text {mix }}$ and $c_{\text {mix }}$ has also led to uncertainty in $J_{\text {mix }}$. When comparing calculated values of $Q_{\text {mix }}$ with manual stream discharge measurements taken at various locations between the two gauging stations, the error in the corresponding estimated values is ca. $\pm 10 \%$. Furthermore, the uncertainty in the laboratory 
analyses of chlorinated ethenes is expected to be on the order of $\pm 10 \%$. Based on these uncertainties, a range for $J_{\text {mix }}$ of total chlorinated ethenes has been found to be 814 to $1216 \mathrm{~kg} / \mathrm{y}$ (PCE eq) (SI Figure S8).

Regarding the uncertainty in $J_{G W}$, it could be decreased by a more frequent monitoring of the culvert discharge, which could provide information on the possible temporal variation in the contaminant input from the culverts. Finally, investigation of the attenuation processes could determine whether similar values of $J_{C P}$ and $J_{G W}$ should be expected.

\subsection{Perspectives}

Considering the inherent uncertainties associated with this study, as well as the high relative uncertainties reported by the literature (Troldborg et al., 2012), the contaminant mass discharge quantified by the Darcybased and PVP-based methods are similar, hence we cannot conclude than one method performs better than the other. The stream bank estimates compared reasonably well with the in-stream value. Hence, when quantifying contaminant mass discharge close to streams where the groundwater flow field is multi -directional, the combination of PVPs and multi-level groundwater sampling seems to provide a useful extension to the Darcy-based methods.

Notably, the in-stream contaminant mass discharge is valuable when assessing various control plane approaches and their related field methods, as it helps to ensure that the entire contaminant mass has been accounted for. Moreover, the low costs and simplicity associated with stream water sampling and stream discharge measurements makes the in-stream contaminant mass discharge a key parameter in risk assessment (see also Sonne et al., 2017). Stream water concentrations, however, may be below the quantification limit due to dilution (e.g. Conant et al., 2004; Westbrook et al., 2005). In these cases a second look at the importance, i.e. risk posed to the stream, may be warranted even with a notably large contaminant mass discharge taking place.

\section{Conclusion}

We quantified the contaminant mass of chlorinated ethenes discharging through a control plane at the bank of a low-land Danish stream using a concentration grid obtained from ordinary kriging. The grid was combined with: 1) specific discharge obtained from Darcy's law using the geometric mean of the hydraulic conductivity and a gradient measured at the groundwater-surface water interface; and 2) two different specific discharge fields created from PVP data (seepage velocities). 
The fully mixed in-stream contaminant mass discharge was quantified from a relationship between completely mixed stream concentrations and the corresponding stream discharge, and found to be $1005 \mathrm{~kg} / \mathrm{y}$ (PCE eq). The relationship was found to be robust with an $R^{2}$-value of 0.86 for total chlorinated ethenes, indicating that the contaminant mass discharge did not strongly depend on stream discharge and thus varied little with time. Corrections for culvert input, as well as for in-stream contaminant mass entering upstream of the discharge zone were made to obtain a groundwater-borne in-stream contaminant mass discharge of $558 \mathrm{~kg} / \mathrm{y}$ (PCE eq).

The contaminant mass discharges at the stream bank were estimated to 372, 204 and $269 \mathrm{~kg} / \mathrm{y}$ (PCE eq.) using a constant Darcy-based, a constant PVP-based and a varying PVP-based specific discharge field, respectively, corresponding to $67 \%, 37 \%$ and $48 \%$ of the in-stream value.

The difference between the estimates of contaminant mass discharging through the control plane at the stream bank and the groundwater-borne in-stream contaminant mass discharge is thought to be caused by a combination of the following factors: 1) missed high concentration zones, 2) high concen tration zones located in fast flow conduits, and 3) uncertainty in the estimate of contaminant input from the culverts.

The results obtained using PVPs suggest that the combination of direct groundwater velocity measurements from PVPs and multi-level groundwater sampling provides a useful extension of Darcy-based methods when quantifying the contaminant mass discharge close to streams. In addition, this study demonstrates the usefulness of the in-stream contaminant mass discharge approach for risk asse ssment, and we recommend that it is quantified before extensive sub surface investigations are initiated.

\section{Acknowledgement}

This study was conducted as part of the project "Advancing GEOlogical, geophysical and CONtaminant monitoring technologies for contaminated site investigation" (GEOCON), which was funded by The Innovation Fund Denmark. Collection of field data was additionally supported by the Region of Southern Denmark. Special thanks are also extended to colleagues at DTU environment, namely Bent H. Skov, Jens S. Sørensen, Flemming Møller and Louise Rosenberg for assistance in the field; Mikael E. Olson, Christina M. Hagberg and Hanne Bøggild for carrying out the chemical analyses; and Philip J. Binning and Pernille A. Marker for valuable inputs and advice regarding data processing.

\section{References}


Abe, Y., Aravena, R., Zopfi, J., Parker, B., Hunkeler, D., 2009. Evaluating the fate of chlorinated ethenes in streambed sediments by combining stable isotope, geochemical and microbial methods. J. Contam. Hydrol. 107, 10-21. doi:10.1016/j.jconhyd.2009.03.002

Aisopou, A., Bjerg, P.L., Sonne, A.T., Balbarini, N., Rosenberg, L., Binning, P.J., 2015. Dilution and volatilization of groundwater contaminant discharges in streams. J. Contam. Hydrol. 172, 71-83.

doi:10.1016/j.jconhyd.2014.11.004

Annable, M.D., Hatfield, K., Cho, J., Klammler, H., Parker, B.L., Cherry, J.A., Rao, P.S.C., 2005. Field -scale evaluation of the passive flux meter for simultaneous measurement of groundwater and contaminant fluxes. Environ. Sci. Technol.39, 7194-7201. doi:10.1021/es050074g

Balbarini, N., Boon, W.M., Nicolajsen, E., Nordbotten, J.M., Bjerg, P.L., Binning, P.J., 2016. A 3-D model of the influence of meanders on groundwater discharge to streams. J. Hydrol.

Barbaro, J.R., Neupane, P.P., 2006. Use of plume mapping data to estimate chlorinated solvent mass loss. Gr. Water Monit. Remediat. 26, 115-127. doi:10.1111/j.1745-6592.2006.00117.x

Barlebo, H.C., Hill, M.C., Rosbjerg, D., Jensen, K.H., 1998. Concentration Data and Dimensionality in Groundwater Models: Evaluation Using Inverse Modelling. Nord. Hydrol. 29, 149-178.

Basu, N.B., Rao, P.S.C., Poyer, I.C., Annable, M.D., Hatfield, K., 2006. Flux-based assessment at a manufacturing site contaminated with trichloroethylene. J. Contam. Hydrol. 86, 105-127. doi:10.1016/j.jconhyd.2006.02.011

Bauer, S., Bayer-Raich, M., Holder, T., Kolesar, C., M??ller, D., Ptak, T., 2004. Quantification of groundwater contamination in an urban area using integral pumping tests. J. Contam. Hydrol. 75, 183-213. doi:10.1016/j.jconhyd.2004.06.002

Bayer-Raich, M., Jarsj??, J., Liedl, R., Ptak, T., Teutsch, G., 2006. Integral pumping test analyses of linearly sorbed groundwater contaminants using multiple wells: Inferring mass flows and natural attenuation rates. Water Resour. Res. 42, 1-10. doi:10.1029/2005WR004244

Béland-Pelletier, C., Fraser, M., Barker, J., Ptak, T., 2011. Estimating contaminant mass discharge: A field comparison of the multilevel point measurement and the integral pumping investigation approaches and their uncertainties. J. Contam. Hydrol. 122, 63-75. doi:10.1016/j.jconhyd.2010.11.004

Bockelmann, A., Zamfirescu, D., Ptak, T., Grathwohl, P., Teutsch, G., 2003. Quantification of mass fluxes and natural attenuation rates at an industrial site with a limited monitoring network: A case study. J. Contam. Hydrol.60, 97-121. doi:10.1016/S0169-7722(02)00060-8

Bohling, G.C., Liu, G., Knobbe, S.J., Reboulet, E.C., Hyndman, D.W., Dietrich, P., Butler, J.J., 2012. Geostatistical analysis of centimeter-scale hydraulic conductivity variations at the MADE site. Water Resour. Res. 48, 115. doi:10.1029/2011WR010791

Bouwer, H., Rice, R.C., 1976. A slug test for determining hydraulic conductivity of unconfined aquife rs with completely or partially penetrating wells. Water Resour. Res. 12, 423-428.

doi:10.1029/WR012i003p00423 
Cai, Z., Wilson, R.D., Cardiff, M.A., Kitanidis, P.K., 2011. Increasing Confidence in Mass Discharge Estimates Using Geostatistical Methods. Ground Water 49, 197-208. doi:10.1111/j.1745-6584.2010.00709.x

Calver, A., 2001. Riverbed Permeabilities: Information from Pooled Data. Ground Water 39, 546-553.

Chapman, S.W., Parker, B.L., Cherry, J.A., Aravena, R., Hunkeler, D., 2007. Groundwater-surface water interaction and its role on TCE groundwater plume attenuation. J. Contam. Hydrol. 91, 203-232. doi:10.1016/j.jconhyd.2006.10.006

Conant, B., Cherry, J.A., Gillham, R.W., 2004. A PCE groundwater plume discharging to a river: Influence of the streambed and near-river zone on contaminant distributions. J. Contam. Hydrol. 73, 249-279. doi:10.1016/j.jconhyd.2004.04.001

Devlin, J.F., 2016. Sensitivity analyses of the theoretical equations used in point velocity probe (PVP) data interpretation. J. Contam. Hydrol. 192, 140-145. doi:10.1016/j.jconhyd.2016.07.004

Devlin, J.F., Tsoflias, G., McGlashan, M., Schillig, P., 2009. An inexpensive multilevel array of sensors for direct ground water velocity measurement. Gr. Water Monit. Remediat. 29, 73-77. doi:10.1111/j.17456592.2009.01233.x

DMI, 2016. Vejrarkiv [Homepage of Danmarks Meterol ogiskeInstitut] Online available.

Ellis, P.A., Rivett, M.O., 2007. Assessing the impact of VOC-contaminated groundwater on surface water at the city scale 91, 107-127. doi:10.1016/j.jconhyd.2006.08.015

Fischer, H.B., List, E.J., Koh, R.C.Y., Imberger, J., Broooks, N.H., 1979. Mixing in Inland and Coastal Waters. AcademicPress, San Diego.

Freitas, J.G., Rivett, M.O., Roche, R.S., Durrant, M., Walker, C., Tellam, J.H., 2015. Heterogeneous hyporheic zone dechlorination of a TCE groundwater plume discharging to an urban river reach. Sci. Total Environ. 505, 236-252. doi:10.1016/j.scitotenv.2014.09.083

Goltz, M.N., Close, M.E., Yoon, H., Huang, J., Flintoft, M.J., Kim, S., Enfield, C., 2009. Validation of two innovative methods to measure contaminant mass flux in groundwater. J. Contam. Hydrol. 106, 51-61. doi:10.1016/j.jconhyd.2009.01.001

Herold, M., Ptak, T., Bayer-Raich, M., Wendel, T., Grathwohl, P., 2009. Integral quantification of contaminant mass flow rates in a contaminated aquifer: Conditioning of the numerical inversion of concentration -time series. J. Contam. Hydrol. 106, 29-38. doi:10.1016/j.jconhyd.2008.12.006

Heron, G., Bjerg, P.L., Gravesen, P., Ludvigsen, L., Christensen, T.H., 1998. Geology and sediment geochemistry of a landfill leachate contaminated aquifer (Grindsted, Denmark). J. Contam. Hydrol. 29, 301-317.

Hinsby, K., Bjerg, P., Andersen, L., Skov, B., Clausen, E., 1992. A mini slug test method for determination of a local hydraulic conductivity of an unconfined sandy aquifer. J. Hydrol. 136, 87-106. doi:10.1016/00221694(92)90006-H

ITRC, 2010. Use and measurement of mass flux and mass discharge. Interstate Technology \& Regulatory Council, Integrated DNAPLSite Strategy Team. 
Jarsjö, J., Bayer-Raich, M., Ptak, T., 2005. Monitoring groundwater contamination and delineating source zones at industrial sites: Uncertainty analyses using integral pumping tests. J. Contam. Hydrol. 79, 107-134. doi:10.1016/j.jconhyd.2005.05.011

Kalbus, E., Reinstorf, F., Schirmer, M., 2006. Measuring methods for groundwater - surface water interactions: a review. Hydrol. Earth Syst. Sci. 10, 873-887. doi:10.5194/hess-10-873-2006

Karan, S., Engesgaard, P., Rasmussen, J., 2014. Dynamic streambed fluxes during rainfall-runoff events. Water Resour. Res. 2293-2311. doi:10.1002/2013WR014155. Received

Kasahara, T., Hill, A.R., 2007. Lateral Hyporheic Zone Chemistry in an Artificially Constructed Gravel Bar and a Re-Meandered Stream Channel, Southern Ontario, Canada1. J. Am. Water Resour. Assoc. 43, 1257-1269.

Keery, J., Binley, A., Crook, N., Smith, J.W.N., 2007. Temporal and spatial variability of groundwater-surface water fluxes: Development and application of an analytical method using tem perature time series. J. Hydrol.336, 1-16. doi:10.1016/j.jhydrol.2006.12.003

Kempf, A., Divine, C.E., Leone, G., Holland, S., Mikac, J., 2013. Field Performance of Point Velocity probes at a Tidally Influenced Site. Remediat. J. 23, 37-61. doi:DOI:10.1002/rem.21337

Klammler, H., Hatfield, K., Guimarães Da Luz, J.A., Annable, M.D., Newman, M., Cho, J., Peacock, A., Stucker, V., Ranville, J., Cabaniss, S.A., Rao, P.S.C., 2012. Contaminant discharge and uncertainty estimates from passive flux meter measurements. Water Resour. Res. 48. doi:10.1029/2011WR010535

Kübert, M., Finkel, M., 2006. Contaminant mass discharge estimation in groundwater based on multi-level point measurements: A numerical evaluation of expected errors. J. Contam. Hydrol. 84, 55-80. doi:10.1016/j.jconhyd.2005.12.003

Labaky, W., Devlin, J.F., Gillham, R.W., 2009. Field comparison of the point velocity probe with other groundwatervelocity measurement methods. Water Resour. Res. 46, 1-9. doi:10.1029/2008WR007066

Labaky, W., Devlin, J.F., Gill ham, R.W., 2007. Probe for measuring groundwater velocity at the centimeter scale. Environ. Sci. Technol. 41, 8453-8458. doi:10.1021/es0716047

Lee, S., Kaown, D., Lee, K., 2015. Evaluation of the fate and transport of chlorinated ethenes in a complex groundwater system discharging to a stream in Wonju, Korea 182, 231-243.

Lorah, M.M., Olsen, L.D., 1999. Field evidence of anaerobic biodegradation. Water Resour. 35, 3811-3827.

McKnight, U.S., Funder, S.G., Rasmussen, J.J., Finkel, M., Binning, P.J., Bjerg, P.L., 2010. An integrated model for assessing the risk of TCE groundwater contamination to human receptors and surface water ecosystems. Ecol. Eng. 36, 1126-1137. doi:10.1016/j.ecoleng.2010.01.004

Milosevic, N., Thomsen, N.I., Juhler, R.K., Albrechtsen, H.J., Bjerg, P.L., 2012. Identification of discharge zones and quantification of contaminant mass discharges into a local stream from a landfill in a heterogeneous geologic setting. J. Hydrol. 446-447, 13-23. doi:10.1016/j.jhydrol.2012.04.012

Newell, C.J., Farhat, S.K., Adamson, D.T., Looney, B.B., 2011. Contaminant Plume Classification System Based on Mass Discharge. Ground Water 49, 914-919. doi:10.1111/j.1745-6584.2010.00793.x 
Nowinski, J.D., Cardenas, M.B., Lightbody, A.F., 2011. Evolution of hydraulic con ductivity in the floodplain of a meandering river due to hyporheic transport of fine materials. Geophys. Res. Lett. 38, 2-6. doi:10.1029/2010GL045819

Rasmussen, J.J., McKnight, U.S., Sonne, A.T., Wiberg-Larsen, P., Bjerg, P.L., 2016. Legacy of a Chemical Factory Site: Contaminated Ground water Impacts Stream Macroinvertebrates. Arch. Environ. Contam. Toxicol. 70, 219-230. doi:10.1007/s00244-015-0211-2

Rovey, C.W., Cherkauer, D.S., 1995. Scale Dependency of Hydraulic Conductivity Measurements. Ground Water 33, 769-780. doi:10.1111/j.1745-6584.1995.tb00023.x

Rügge, K., Bjerg, P.L., Pedersen, J.K., Mosbæk, H., Christensen, T.H., 1999. An anaerobic field injection experiment in a landfill leachate plume, Grindsted, Denmark. 1. Experimental setup, tracer movement, and fate of aromatic and chlorinated compounds. Water Resour. Res. 35, 1231-1246.

doi:10.1029/1998WR900101

Rønde, V., 2014. Quantification of stream-aquifer contaminant mass discharge using Point-Velocity Probes (PVP) at the stream reach scale (Grindsted, Denmark). Master's thesis. Department of Environmental Engineering. DTU, Lyngby, Denmark.

Schillig, P.C., 2012. VelProbePE: An automated spreadsheet program for interpreting point velocity probe breakthrough curves. Comput. Geosci. 39, 161-170. doi:10.1016/j.cageo.2011.06.007

Schillig, P.C., Devlin, J.F., Roberts, J.A., Tsoflias, G.P., McGlashan, M.A., 2011. Transient Heterogeneity in an Aquifer Undergoing Bioremediation of Hydrocarbons. Ground Water 49, 184-196. doi:10.1111/j.17456584.2010.00682.x

Schillig, P.C., Devlin, J.F., Rudolph, D., 2016. Upscal ing Point Velocity Measurements to Characterize a Glacial Outwash Aquifer. Ground Water 54, 394-405. doi:10.1111/gwat.12357

Sebok, E., Duque, C., Engesgaard, P., Boegh, E., 2015. Spatial variability in streambed hydraulic conductivity of contrasting stream morphologies: Channel bend and straight channel. Hydrol. Process. 29, 458-472. doi:10.1002/hyp.10170

Silliman, S.E., Mantz, G., 2000. The effect of measurement error on estimating the hydraulic gradient i $n$ three dimensions. Ground Water 38, 114-120.

Sonne, A.T., McKnight, U.S., Rønde, V., Bjerg, P.L., 2017. Assessing the chemical contamination dynamics in a mixed land use stream system. Water Res. 125, 141-151. doi:10.1016/j.watres.2017.08.031

Springer, R.K., Gelhar, L.W., 1991. Characterization of large-scale aquifer heterogeneity in glacial outwash by analysis of slug tests with oscillatory responses, in: Mallard, G.E. and Aronson, D.A. (Eds.), U.S. Geological Survey Toxic Substances Hydrology Program--Proceedings of the technical meeting, Monterey, California, March 11-15, 1991. Water-Resources Investigation Report 91-4034.

Storey, R.G., 2003. Factors controlling riffle-scale hyporheic exchange flows and their seasonal changes in a gaining stream: A three-dimensional groundwater flow model. Water Resour. Res. 39, 1-17.

doi:10.1029/2002WR001367 
Troldborg, M., Nowak, W., Lange, I. V., Santos, M.C., Binning, P.J., Bjerg, P.L., 2012. Application of Bayesian geostatistics for evaluation of mass discharge uncertainty at contaminated sites. Water Resour. Res. 48, 1-19. doi:10.1029/2011WR011785

Troldborg, M., Nowak, W., Tuxen, N., Bjerg, P.L., Helmig, R., Binning, P.J., 2010. Uncertainty evaluation of mass discharge estimates from a contaminated site using a fully Bayesian framework. Water Resour. Res. 46, 119. doi:10.1029/2010WR009227

Verreydt, G., van Keer, I., Bronders, J., Diels, L., Vanderauwera, P., 2012. Flux-based risk management strategy of groundwater pollutions: The CMF approach. Environ. Geochem. Health 34, 725-736.

doi:10.1007/s10653-012-9491-x

Weatherill, J., Krause, S., Voyce, K., Drijfhout, F., Levy, A., Cassidy, N., 2014. Nested monitoring approaches to delineate groundwater trichloroethene discharge to a UK lowland stream at multiple spatial scales. J. Contam. Hydrol. 158, 38-54. doi:10.1016/j.jconhyd.2013.12.001

Westbrook, S.J., Rayner, J.L., Davis, G.B., Clement, T.P., Bjerg, P.L., Fisher, S.J., 2005. Interaction between shallow groundwater, saline surface water and contaminant discharge at a seasonally and tidally forced estuarine boundary. J. Hydrol. 302, 255-269. doi:10.1016/j.jhydrol.2004.07.007

Wroblicky, G.J., Campana, M.E., Dahm, N., 1998. Seasonal variation in surface-subsurface water exchange and lateral hyporheic area of two stream-aquifer systems. Water Resour. 34, 317-328.

Zeru, A., Schäfer, G., 2005. Analysis of groundwater contamination using concentration-time series recorded during an integral pumping test: Bias introduced by strong concentration gradients within the plume.J. Contam. Hydrol. 81, 106-124. doi:10.1016/j.jconhyd.2005.08.005 


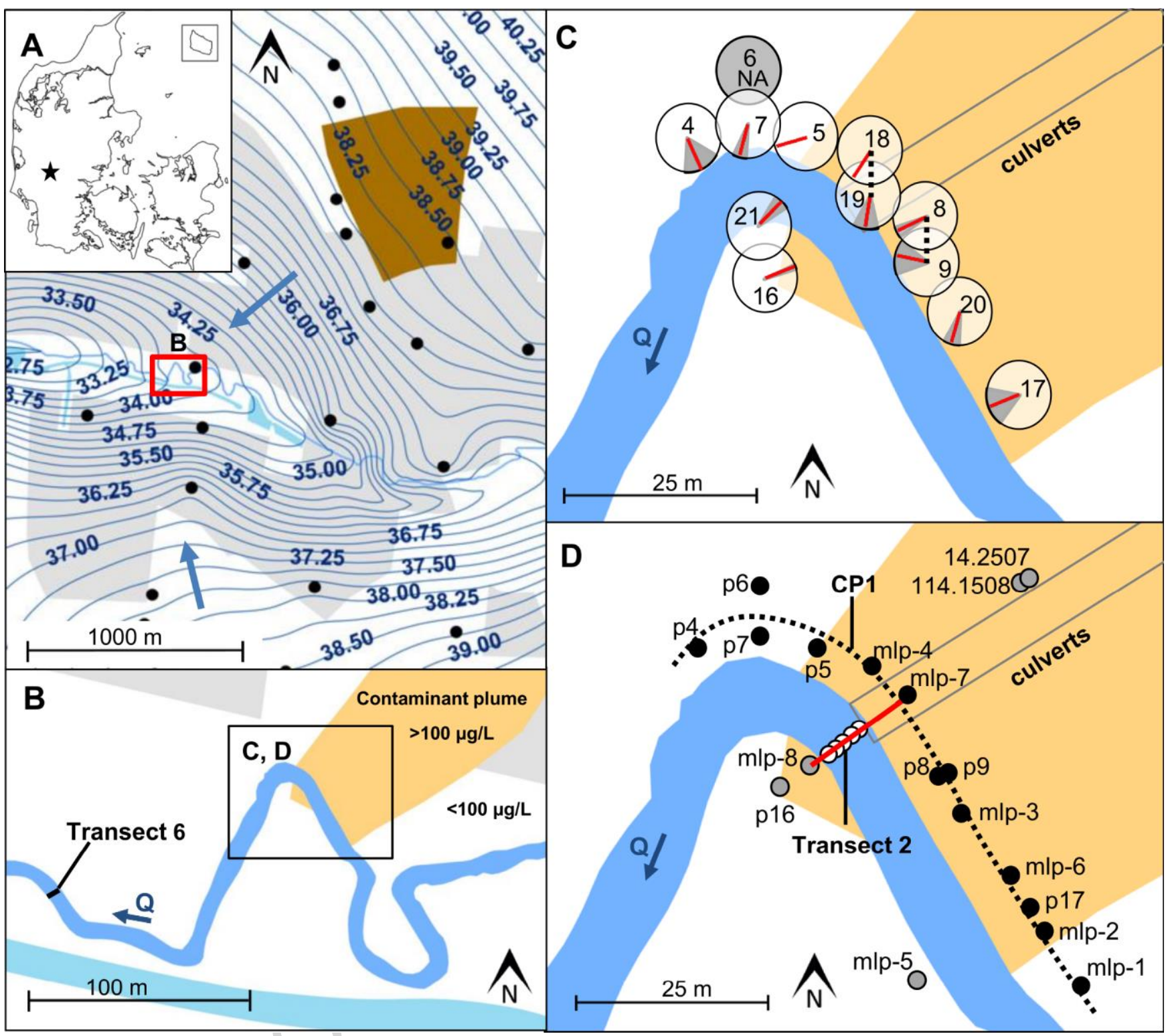




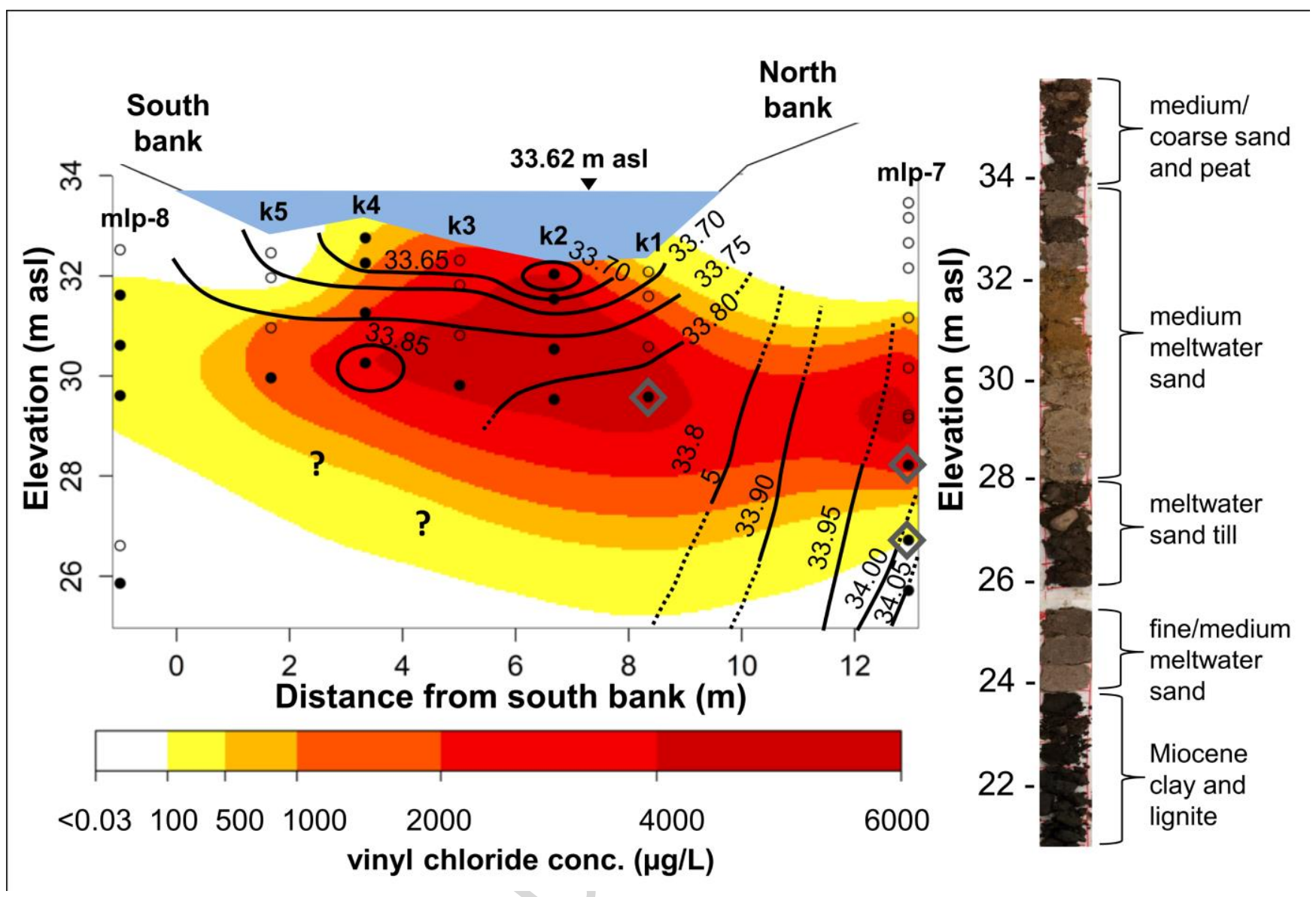




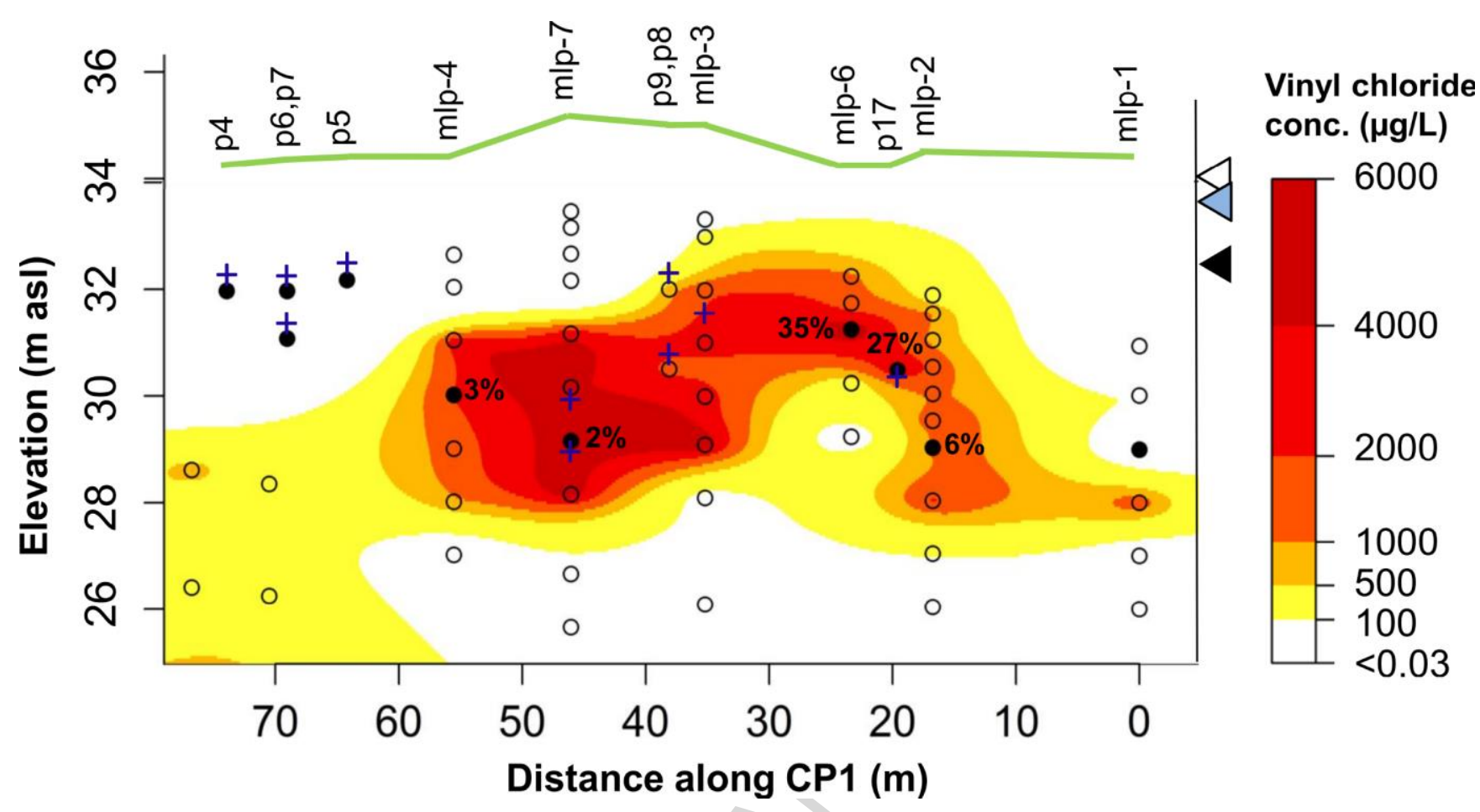




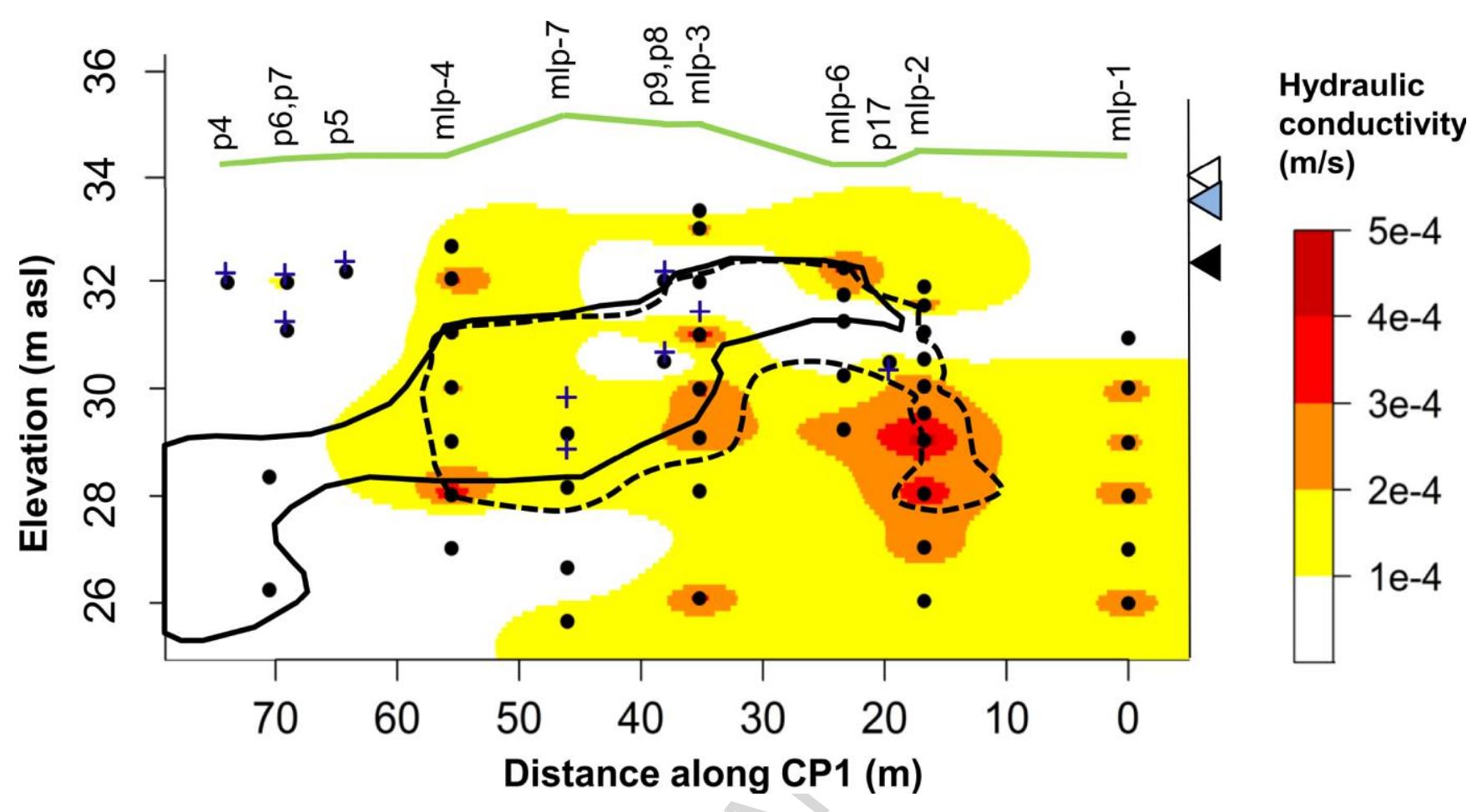




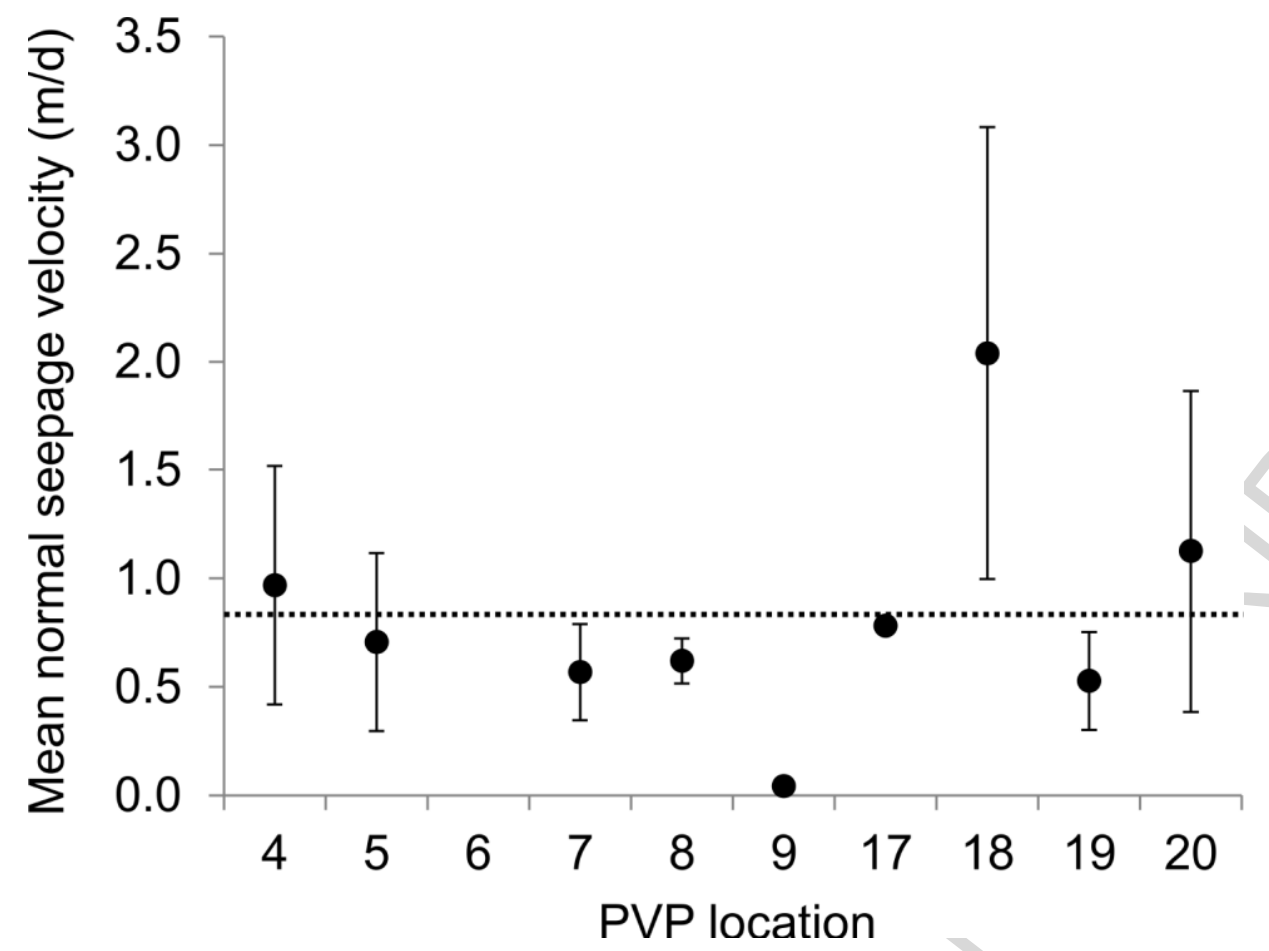




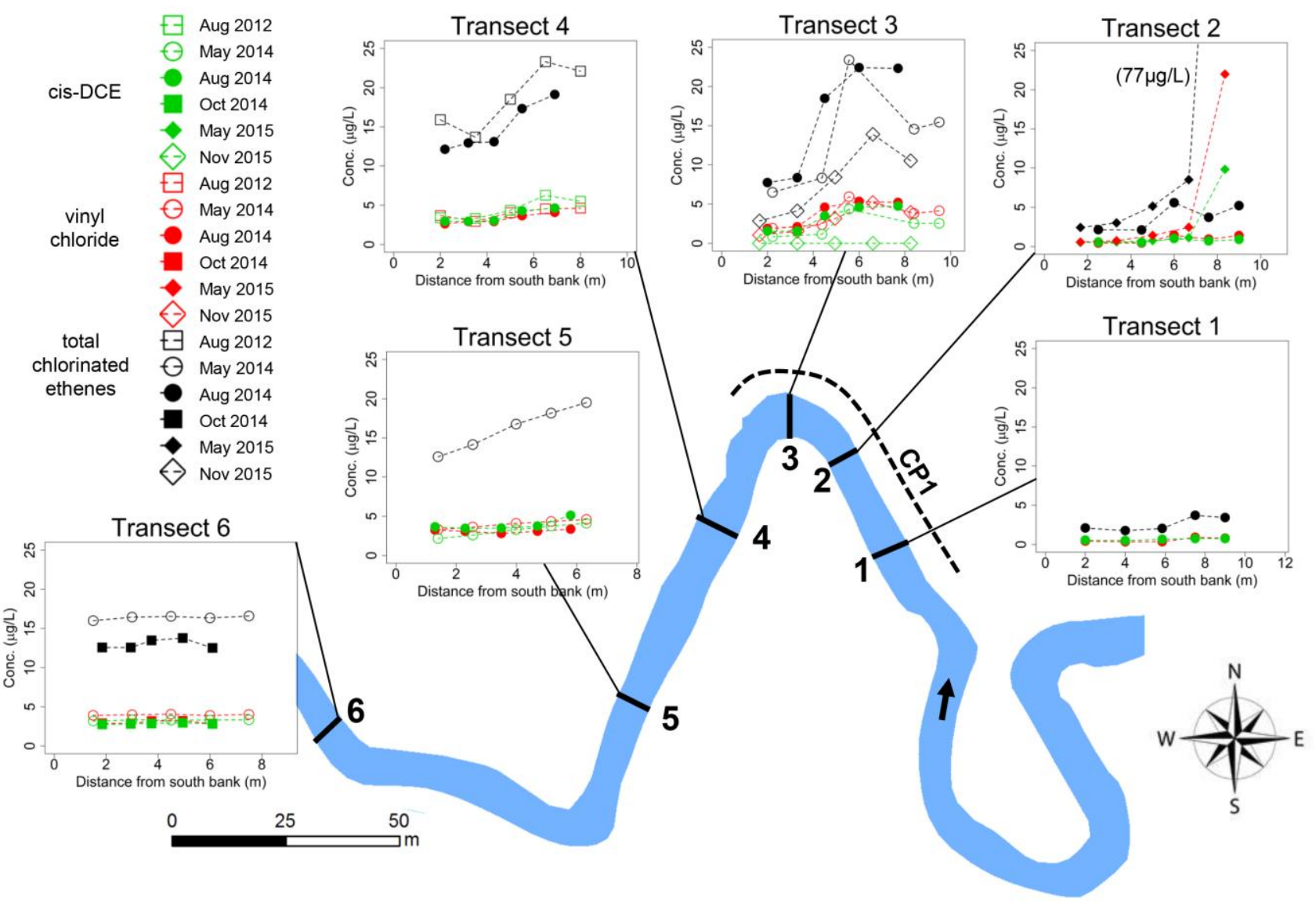




\section{A Total chlorinated ethenes}

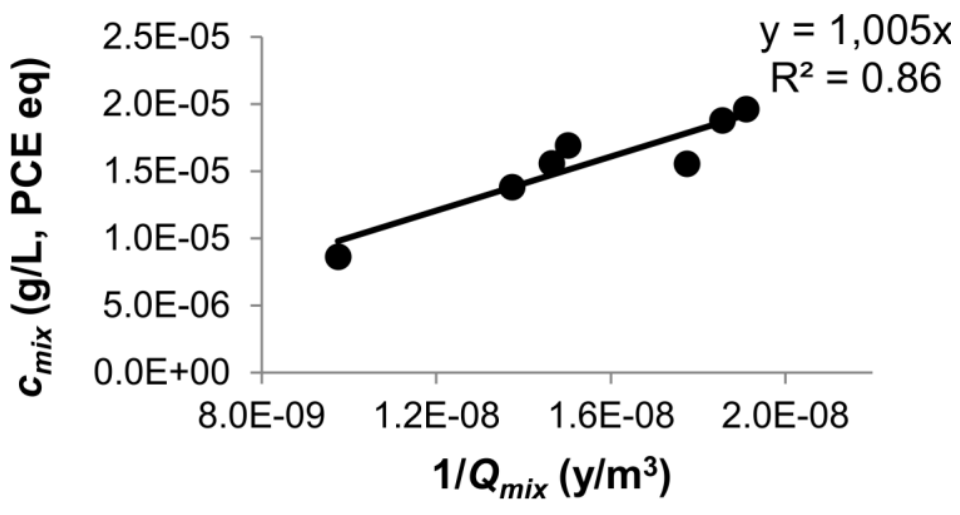

B cis-DCE
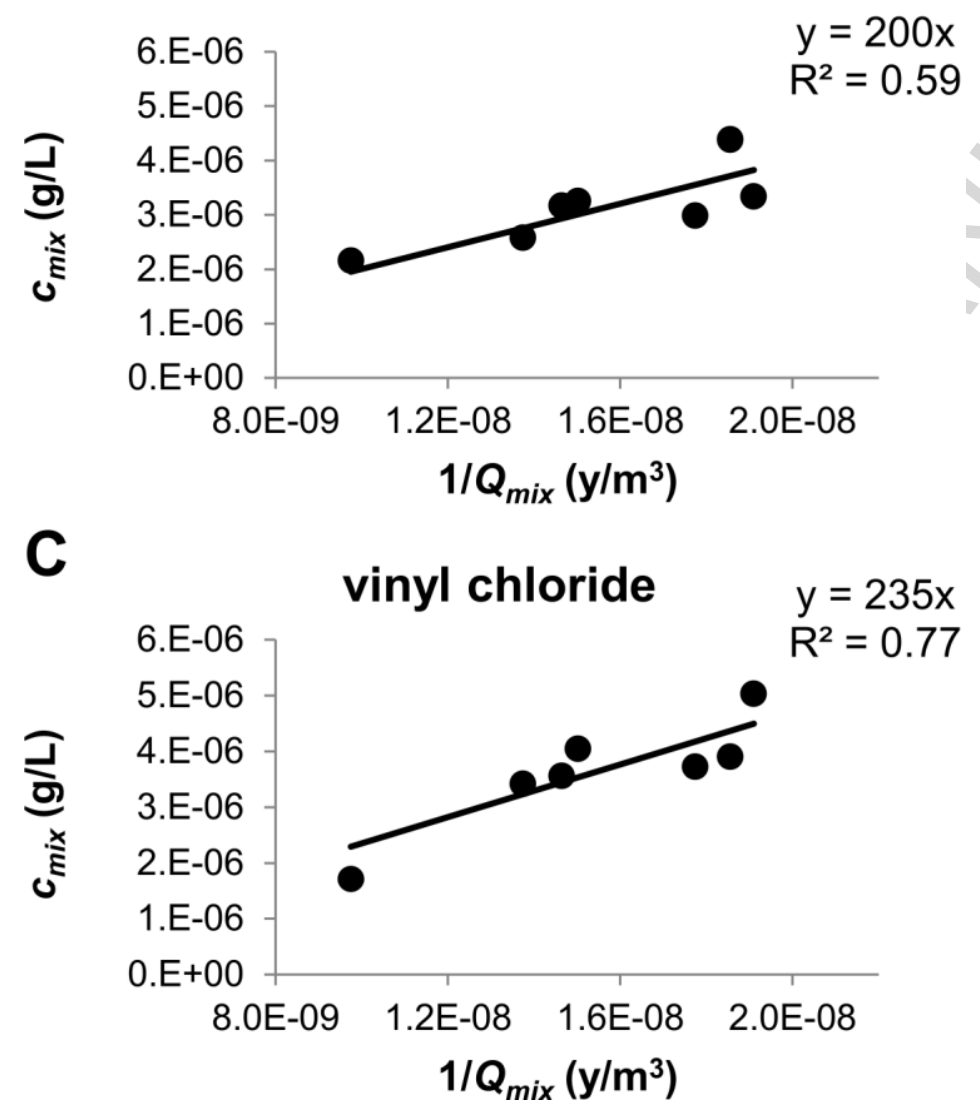


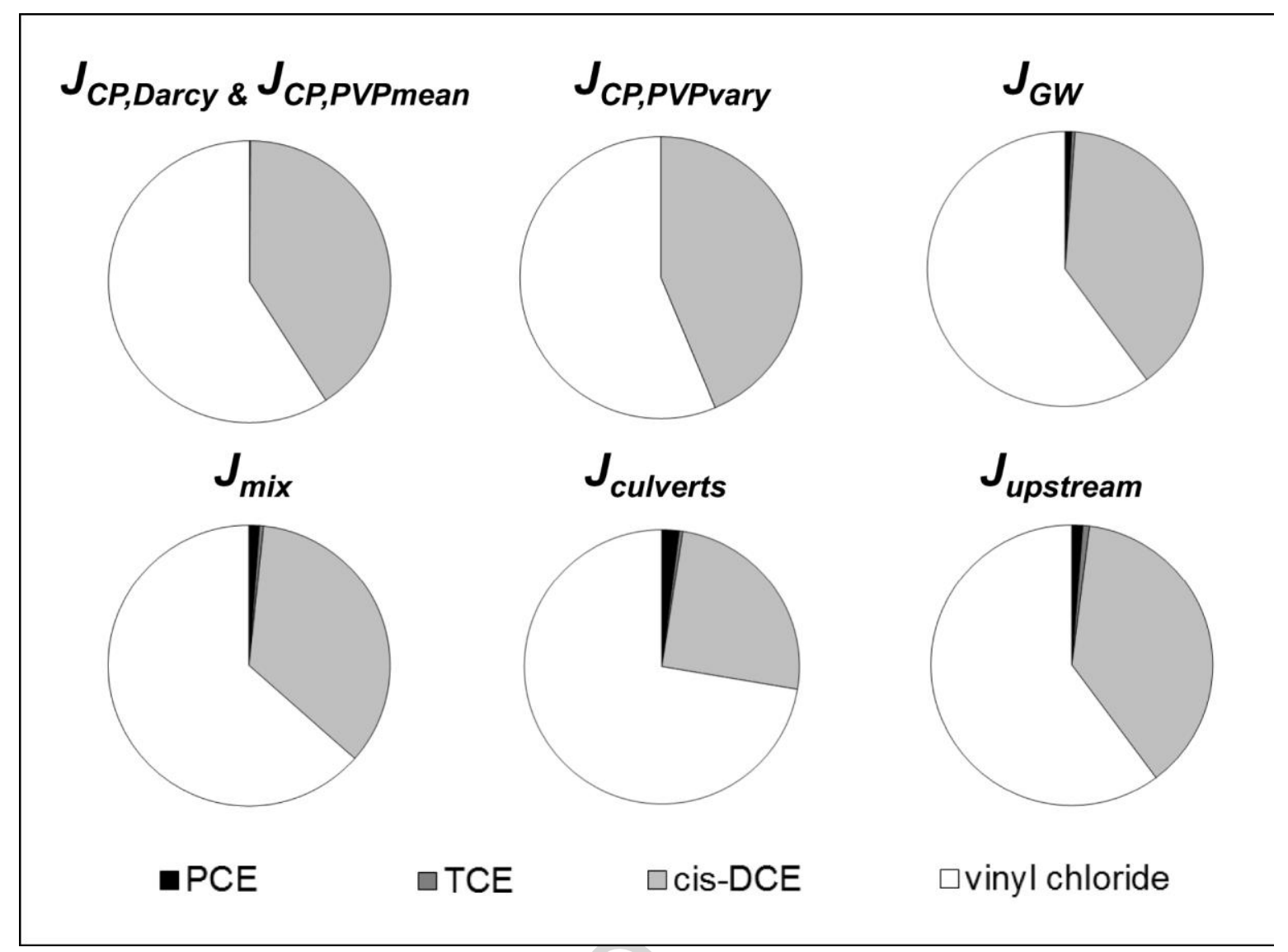


Highlights

- PVPs can measure seepage velocity and flow angle near streams with a high precision

- PVP data are useful for contaminant mass discharge (CMD) quantification to streams

- CMD estimation using PVP data yields results comparable to Darcy-based methods

- The in-stream CMD can help account for the total contaminant mass at the streambank 